\title{
Sonography of Non-neoplastic Disorders of the Hand and Wrist Tendons
}

\author{
Salvatore Gitto, MD (D), Anna Guja Draghi, Ferdinando Draghi, MD
}

Received February 8, 2017, from the Postgraduate School in Radiodiagnostics, Università Degli Studi di Milano, Milan, Italy (S.G.); and Radiology Institute, Fondazione Istituto di Ricovero e Cura a Carattere Scientifico Policlinico San Matteo, Università Degli Studi di Pavia, Pavia, Italy (A.G.D., F.D.). Manuscript accepted for publication March 27, 2017.

Address correspondence to Salvatore Gitto, $\mathrm{MD}$, Postgraduate School in Radiodiagnostics, Università Degli Studi di Milano, Via Festa del Perdono 7, 20122 Milan, Italy.

E-mail:sal.gitto@gmail.com
Tendon disorders commonly cause hand and wrist disability and curtail the performance of work-related duties or routine tasks. Imaging is often needed for diagnosis, but it requires knowledge of the complex anatomic structures of the tendons of the hand and wrist as well as familiarity with related disorders. This review article aims to provide medical professionals with guidelines for the sonographic assessment of the tendons of hand and wrist and related disorders. Sonographic features of tendon disorders affecting the hand and wrist are described here, specifically: infectious tenosynovitis; tendon rupture or tearing; stenosing forms of tenosynovitis such as De Quervain disease and trigger finger; intersection syndrome; insertional tendinopathy; several forms of tendinous instability such as extensor carpi ulnaris instability, climber finger, and boxer knuckle; and tendinopathy in inflammatory rheumatic diseases. Postsurgical evaluation of the hand and wrist tendons is also discussed, including the healthy and pathologic appearances of operated tendons as well as impingement from orthopedic hardware. In conclusion, sonography is effective in assessing the tendons of the hand and wrist and related disorders and represents a valuable tool for diagnosis.

Key Words — hand; musculoskeletal imaging; sonography; tendon; wrist

$\mathrm{T}$ endon disorders are common causes of hand and wrist disability that affect the quality of life and curtail the performance of work-related duties or routine tasks. Overuse in daily life and sports as well as the long and superficial course of these tendons across the wrist and hand represent risk factors for their derangement. ${ }^{1}$ Imaging is often required for diagnosis, but it requires knowledge of the complex structures and anatomic relationships of the tendons of the hand and wrist as well as familiarity with related disorders. As an inexpensive, time-saving, and largely available imaging modality that allows for the focused, dynamic, and comparative evaluation of small superficial structures with high resolution, sonography is valuable for examining the tendons of the hand and wrist. ${ }^{2,3}$ This review article aims to provide medical professionals with simple and systematic guidelines for sonographic assessment of the tendons of hand and wrist and related disorders. These guidelines are generated from the combined experience of our centers, as indicated by the references in the text, with a thorough analysis of the literature from the last 16 years (2001-2016). A systematic search of the literature was performed in PubMed and included original studies and review articles in English dealing with sonographic descriptions of the tendons of the hand and wrist and related disorders. Case reports and case series were selected according to clinical relevance. 


\section{Normal Anatomy and Sonographic Appearance}

\section{Extensor Tendons}

On the dorsal aspect of the wrist, the extensor tendons run through 6 osseofibrous compartments or tunnels that are numbered from first (radial) to sixth (ulnar; (Figure 1). ${ }^{4,5}$ The roof of these compartments is the extensor retinaculum, also known as the dorsal carpal ligament, a fibrous band that spreads obliquely from the radius to the triquetrum and pisiform, becoming thicker at the level of the fourth compartment. Vertical fibrous septa extend downward from the extensor retinaculum, forming the medial and lateral walls of the dorsal compartments, and then attach to the radius, ulna, and distal radioulnar joint. On the dorsal wrist, the main anatomic landmark is the Lister tubercle, a dorsal bony

Figure 1. Tendons of the dorsal wrist. Axial T1-weighted magnetic resonance scan shows, from radial to ulnar: the extensor pollicis brevis and abductor pollicis longus (Ext pb - Abd pl); the extensor carpi radialis brevis and extensor carpi radialis longus (Ext crb - Ext crl); the extensor pollicis longus (Ext pl); the extensor digitorum communis and extensor indicis proprius (Ext dc and Ext ip); the extensor digit minimi proprius (Ext dmp); and the extensor carpi ulnaris (Ext $\mathrm{cu}$ ).

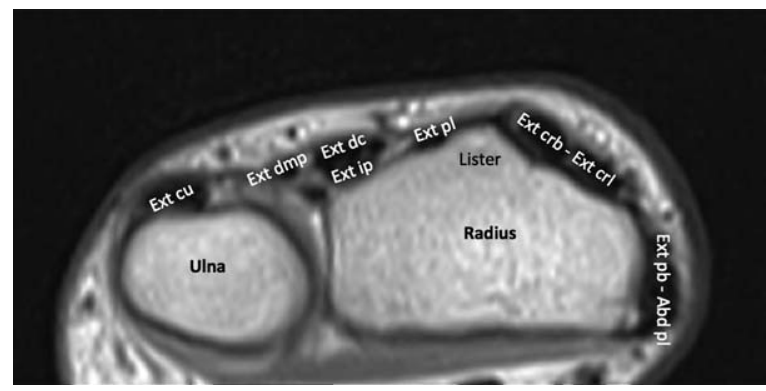

prominence of the distal radius that separates the second and third dorsal compartments. ${ }^{4,5}$ Table 1 details the extensor tendons contained in each dorsal compartment along with their distal insertions.

On the dorsal aspect of the hand, there are 3 variable intertendinous connections called the juncturae tendinae, which link adjacent tendons extending from the middle finger to the index finger and from the ring finger to the middle and little fingers, respectively. ${ }^{6}$ At the level of the metacarpophalangeal joints, the extensor tendons are held in a central position by a fibrous expansion that emits peripheral transverse fibers directed to the volar plate and termed the sagittal bands. ${ }^{7}$

\section{Flexor Tendons}

On the volar aspect of the wrist, there are 3 tendinous layers that correspond to the muscle layers of the anterior forearm. The fourth muscle layer of the anterior forearm includes the pronator quadratus, which originates and inserts within the forearm and does not extend to the wrist (Figure 2). ${ }^{4}$ Table 2 details the flexor tendons grouped in each myotendinous layer along with their distal insertions.

The first tendinous layer is generally superficial to the flexor retinaculum, also known as the transverse carpal ligament, a fibrous band that extends from the scaphoid and trapezium to the pisiform and hamate.,5 Some anatomic variations may occur, however, and mostly involve the palmaris longus muscle. ${ }^{8}$ The flexor tendons of the second and third layers run through the carpal tunnel along with the median nerve. ${ }^{4,5}$ The carpal tunnel is delimited volarly by the flexor retinaculum and dorsally by the carpal bones, specifically the scaphoid and trapezium on the radial side and the pisiform and hamate on the ulnar side. ${ }^{9}$ A further key structure of the

Table 1. Dorsal Osteofibrous Compartments of the Wrist, From Radial (1st) to Ulnar (6th)

\begin{tabular}{|c|c|c|}
\hline Dorsal Compartment & Tendon & Insertion \\
\hline \multirow[t]{2}{*}{1 st } & Abductor pollicis longus & Radial side of the base of the 1st metacarpal \\
\hline & Extensor pollicis brevis & Base of the proximal phalanx of the thumb \\
\hline \multirow[t]{2}{*}{ 2nd } & Extensor carpi radialis longus & Base of the 2nd metacarpal \\
\hline & Extensor carpi radialis brevis & Base of the 3rd metacarpal \\
\hline $3 r d$ & Extensor pollicis longus & Base of the distal phalanx of the thumb \\
\hline \multirow[t]{2}{*}{4 th } & Extensor digitorum communis & $\begin{array}{l}\text { Each of the } 4 \text { tendons directed to digits } 2-5 \text { emits a central terminal } \\
\text { slip inserting into the base of the middle phalanx and medial and } \\
\text { lateral terminal slips inserting into the base of the distal phalanx }\end{array}$ \\
\hline & Extensor indicis proprius & Ulnar side of the middle phalanx of the index finger \\
\hline 5th & Extensor digiti minimi proprius & Ulnar side of the proximal and middle phalanges of the little finger \\
\hline 6th & Extensor carpi ulnaris & Base of the 5th metacarpal \\
\hline
\end{tabular}


volar wrist is the Guyon canal, through which the ulnar neurovascular bundle passes. The Guyon canal extends from the pisiform to the hook of the hamate; it is

Figure 2. Myotendinous layers of the volar aspect of the distal forearm. Axial T1-weighted magnetic resonance scan shows, from radial to ulnar: the first layer containing the flexor carpi radialis (Fle cr), palmaris longus (PI), and flexor carpi ulnaris (Fle cu); the second layer containing the flexor digitorum superficialis (Fle ds); the third layer containing the flexor pollicis longus (Fle pl) and flexor digitorum profundus (Fle dp); and the fourth layer containing the pronator quadratus (Pronator q).

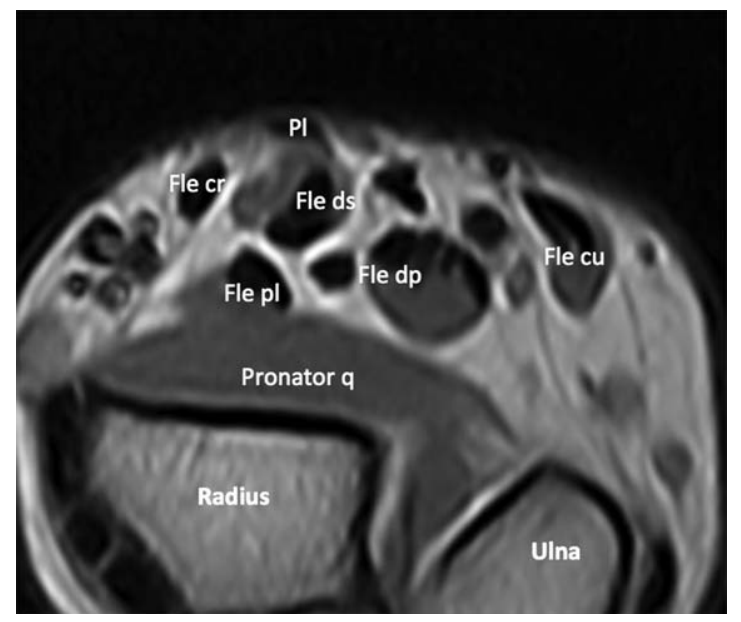

Table 2. Myotendinous Layers of the Volar Wrist, From Superficial (1st) to Deep (3rd)

\begin{tabular}{|c|c|c|}
\hline $\begin{array}{l}\text { Myotendinous } \\
\text { Layer }\end{array}$ & Tendon & Insertion \\
\hline \multirow[t]{3}{*}{$1 \mathrm{st}$} & Flexor carpi radialis & $\begin{array}{l}\text { Base of the } 2 \text { nd and } 3 \text { rd } \\
\text { metacarpals }\end{array}$ \\
\hline & Palmaris longus & Palmar aponeurosis \\
\hline & Flexor carpi ulnaris & $\begin{array}{l}\text { Pisiform, hamate, and base } \\
\text { of the 5th metacarpal }\end{array}$ \\
\hline 2nd & $\begin{array}{l}\text { Flexor digitorum } \\
\text { superficialis }\end{array}$ & $\begin{array}{l}\text { Each of the } 4 \text { tendons } \\
\text { directed to digits } 2-5 \\
\text { emits } 2 \text { bundles that } \\
\text { pass around the deep } \\
\text { flexor tendon before } \\
\text { inserting into the base of } \\
\text { the middle phalanx }\end{array}$ \\
\hline \multirow[t]{2}{*}{$3 r d$} & $\begin{array}{l}\text { Flexor pollicis } \\
\text { longus }\end{array}$ & $\begin{array}{l}\text { Base of the distal phalanx } \\
\text { of the thumb }\end{array}$ \\
\hline & $\begin{array}{l}\text { Flexor digitorum } \\
\text { profundus }\end{array}$ & $\begin{array}{l}\text { Each of the } 4 \text { tendons } \\
\text { directed to digits } 2-5 \\
\text { inserts into the base of } \\
\text { the distal phalanx }\end{array}$ \\
\hline
\end{tabular}

In each myotendinous layer, the flexor tendons are ordered from radial to ulnar. delimited dorsally by the flexor retinaculum and volarly by the palmar carpal ligament, which represents a distal extent of the antebrachial fascia and palmaris brevis muscle. $^{10}$

At the base of each finger, the flexor tendons enter an osteofibrous tunnel formed by the volar aspect of the phalanges and a fibrous sheath composed of the annular and cruciform pulleys. ${ }^{11}$ The annular pulleys keep the flexor tendons closely applied to the phalanges and are numbered from $\mathrm{A} 1$ to $\mathrm{A} 5$ : the $\mathrm{A} 1, \mathrm{~A} 2$, and $\mathrm{A} 3$ pulleys are located at the metacarpophalangeal, proximal interphalangeal, and distal interphalangeal joints, respectively; and the A2 and A4 pulleys are located at the level of the proximal and middle phalanges, respectively. The cruciform pulleys consist of flexible crisscrossing fibers between the components of the annular pulley system and allow flexion of the interphalangeal joints. ${ }^{11,12}$ Only the $\mathrm{A} 1$ and $\mathrm{A} 2$ pulleys are present in the thumb, at the metacarpophalangeal joint and just proximal to the interphalangeal joint, respectively, with one oblique pulley located over the proximal phalanx. ${ }^{6}$

\section{Synovial Sheaths}

With the exception of the flexor carpi ulnaris and palmaris longus, all tendons of the hand and wrist are enclosed within synovial sheaths, which extend a few centimeters proximally in the forearm. ${ }^{6}$ On the dorsal wrist, regardless of the number of tendons it contains, each compartment is generally enveloped by a single synovial sheath. The synovial sheaths of the first, second, third, and sixth dorsal compartments stop immediately proximal to the bases of the metacarpals; those of the fourth and fifth dorsal compartments are prolonged a little more distally along the metacarpals. ${ }^{6}$

In the most superficial tendinous layer of the volar wrist, only the flexor carpi radialis tendon is encircled within a synovial sheath, which ends at the tendon distal insertion. Among the tendons of the second and third layers, the flexor digitorum superficialis and profundus tendons overlap on the ulnar side of the carpal tunnel and share a common sheath. The sheath of the flexor tendons directed to the index, middle, and ring fingers stops about halfway along the metacarpals. For each of the index, middle, and ring fingers, a separate digital synovial sheath generally envelopes the flexor tendons from mid palm to the distal phalanx. The sheath of the flexor tendons directed to the little finger is usually contiguous with their digital synovial sheath. The flexor 
pollicis longus tendon, located at the radial border of the carpal tunnel, has its own sheath that continues along the thumb as far as the tendon distal insertion. ${ }^{6}$

\section{Normal Sonographic Appearance}

Tendons consist of longitudinally oriented bundles of type 1 collagen fibers. On sonograms, collagen bundles are hyperechoic and embedded within a background of a hypoechoic matrix, thus resulting in a fibrillar pattern with multiple parallel lines on longitudinal scans and multiple dots on transverse scans. ${ }^{13,14}$ Synovial sheaths may eventually be depicted as thin echogenic fluidcontaining structures. Retinacula and annular pulleys are best visualized on transverse scans and often appear as hypoechoic bands because of anisotropy. ${ }^{15,16}$

\section{Infectious Tenosynovitis}

The term tenosynovitis indicates an inflammation of the tendon synovial sheath and is common in the wrist and hand, as almost all tendons are enclosed within a synovial sheath. Specifically, it may affect the proximal portion of the extensor tendons, the flexor carpi radialis (Figure 3), and the flexor tendons that pass through the carpal tunnel (Figure 4). The etiology mainly includes infections, local trauma and overuse, systemic inflammatory disorders, impingement from orthopedic hardware, carpal bossing, or fractured bones. ${ }^{17}$ Noninfectious forms of tenosynovitis will be discussed later in the article.

Figure 3. Schematic diagram of the flexor carpi radialis. The flexor carpi radialis, shown here in gray, belongs to the most superficial myotendinous layer of the anterior forearm and is located laterally. Its tendon fibers attach to the second metacarpal, sending a slip to the third metacarpal. This tendon is surrounded by a synovial sheath that begins approximately $3 \mathrm{~cm}$ above the wrist and ends at its distal insertion.

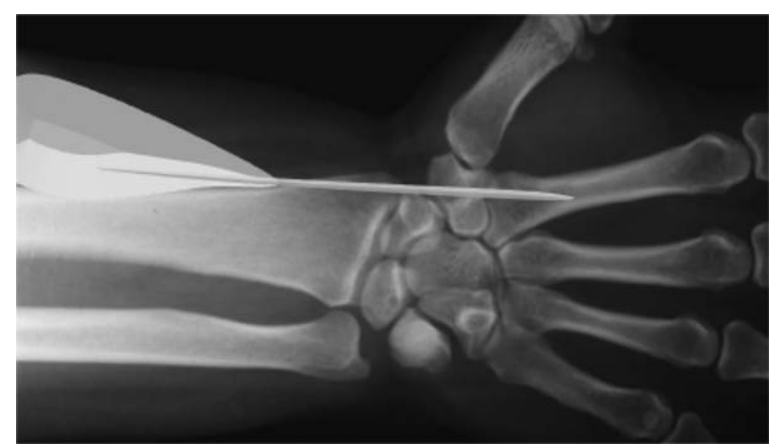

The tendons of the hand and wrist are at risk of infection because of their superficial location. Infectious tenosynovitis may be caused by penetrating injuries with or without a foreign body or, less commonly, spreading of an adjacent soft tissue infection or hematic dissemination. The main risk factors include intravenous drug abuse, diabetes mellitus, and immunosuppression. ${ }^{18} \mathrm{~A}$ variety of microbial agents may be responsible for infectious tenosynovitis: Staphylococcus and Streptococcus species are most often involved in cases of injections, anaerobic agents in diabetic patients, and polymicrobial agents in case of bite wounds; typical or atypical mycobacteria as well as Neisseria gonorrhoeae may also be found. ${ }^{18}$ Clinical findings include local pain, tenderness, and swelling along the affected tendon. Absence of an obvious portal of injury is frequent. ${ }^{19}$ Peculiarly, digital flexor tenosynovitis may irritate the median nerve and cause carpal tunnel syndrome. ${ }^{9}$

Sonographic features of infectious tenosynovitis include intrasynovial fluid, inhomogeneous tendon thickening, peritendinous edema, and hyperemia (Figures 5-7). ${ }^{20-22}$ These findings are, however, nonspecific; thus, a detailed knowledge of the medical history as well as a physical examination is crucial when considering other etiologies of tenosynovitis in the differential diagnosis (Figures 8 and 9). The density of septic intrasynovial fluid varies according to the microbial agent involved. ${ }^{20}$ In the case of flexor tenosynovitis that involves the fingers, intrasynovial fluid often appears lobulated because of the discontinuous array of the

Figure 4. Schematic diagram of the carpal tunnel. The tendons of the flexor digitorum superficialis (Fle ds) and profundus (Fle dp) muscles (4 tendons in each), the flexor pollicis longus tendon (Fle pl), and the median nerve $(\mathrm{Mn})$ all pass through the carpal tunnel on the volar aspect of the wrist. The flexor pollicis longus tendon has its own sheath; the tendons of the flexor digitorum superficialis and profundus tendons share a common sheath.

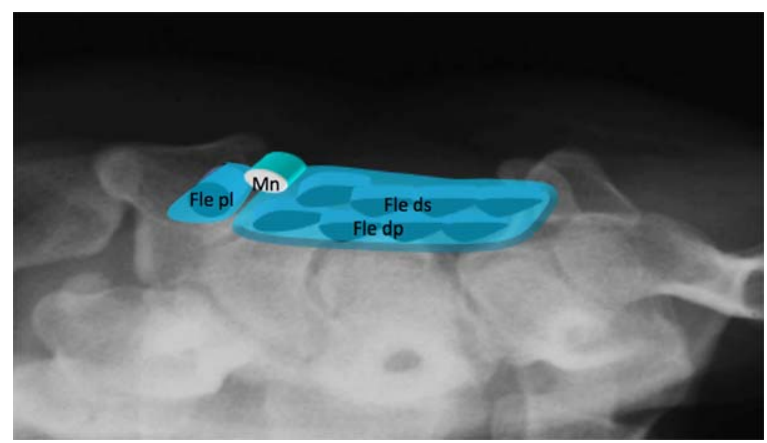


pulleys (Figure 10). ${ }^{16}$ Rice bodies may develop in the case of typical or atypical mycobacterial infections, although they are not specific and can also be identified

Figure 5. Infectious tenosynovitis of the flexor carpi radialis tendon. On a transverse scan, the flexor carpi radialis tendon (Fle $\mathrm{Cr}$ ) is thickened and surrounded by a large intrasynovial effusion that is corpuscular because its septic nature.

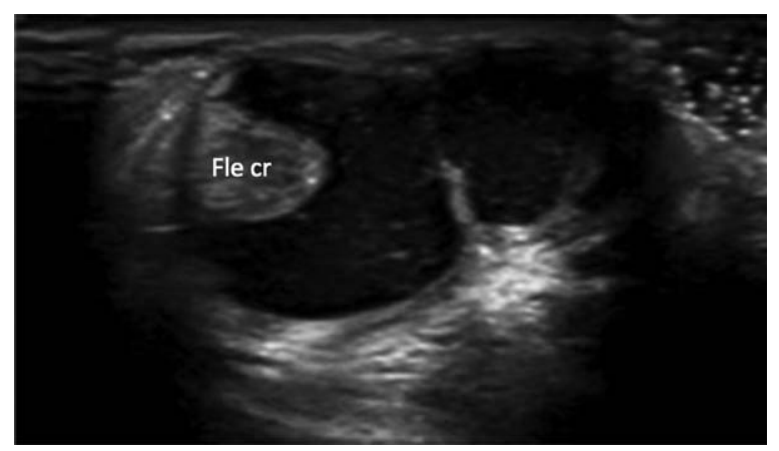

Figure 6. Flexor carpi radialis tenosynovitis. Sonography shows the flexor carpi radialis tendon (Fle cr) surrounded by an intrasynovial effusion, which needs to be distinguished from a ganglion cyst of the radiocarpal joint.

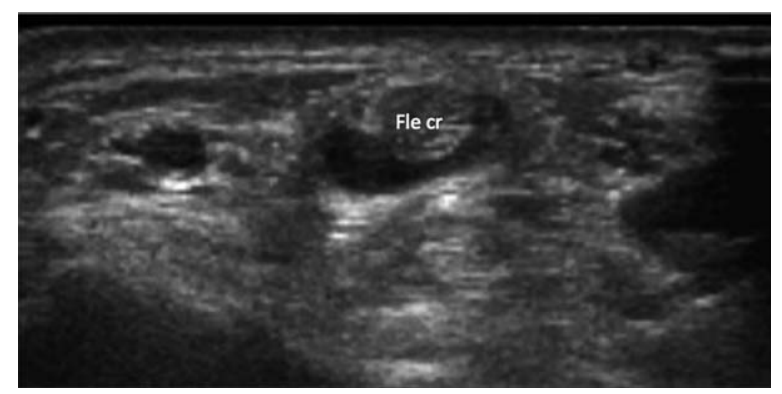

Figure 7. Flexor pollicis longus tenosynovitis and carpal tunnel syndrome. At the level of the carpal tunnel, sonography shows an intrasynovial effusion of the flexor pollicis longus tendon (Fle pl). The median nerve $(\mathrm{Mn})$ is hypoechoic with loss of the fascicular structure.

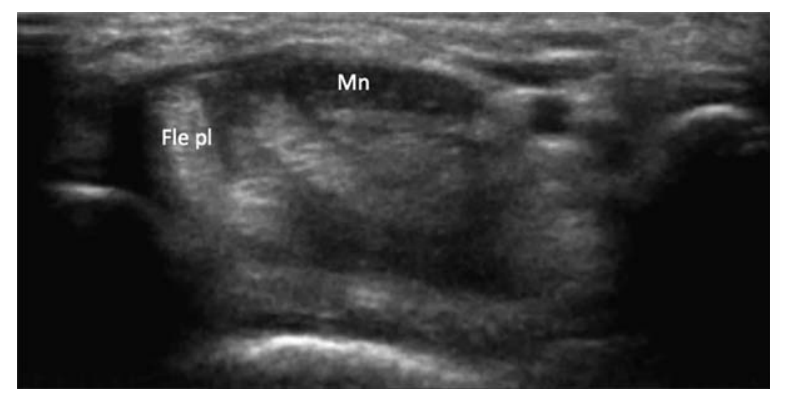

in rheumatoid arthritis and seronegative spondyloarthritis. They are intrasynovial deposits of fibrin that sonographically appear as multiple well-defined hypoechoic

Figure 8. Flexor tenosynovitis and carpal tunnel syndrome in dialysis-associated amyloidosis. On the volar wrist, sonography shows synovial thickening of the flexor carpi radialis tendon (Fle $\mathrm{cr}$ ) and flexor tendons within the carpal tunnel due to deposition of $\beta 2$ microglobulin. The median nerve (Mn) is hypoechoic as a sign of carpal tunnel syndrome.

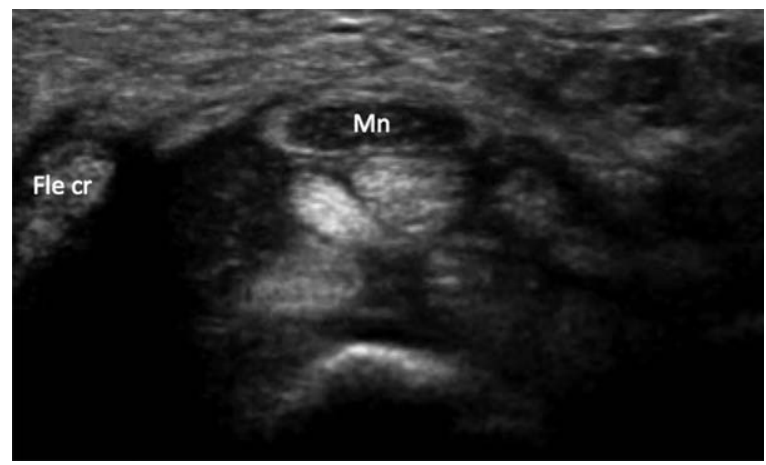

Figure 9. Allergic tenosynovitis of the extensor tendons after surgical excision of a radiocarpal ganglion cyst. Beyond the site of the intersection between the extensor pollicis longus (Ext pl) and the tendons of the second dorsal compartment, sonography shows an intrasynovial effusion of the extensor carpi radialis longus (Ext $\mathrm{crl}$ ), extensor carpi radialis brevis (Ext crb), and extensor digitorum communis and extensor indicis proprius (Ext dc-ip) tendons resulting from an allergic reaction to the sutures (A). On a color Doppler scan, synovial hyperemia is seen (B).
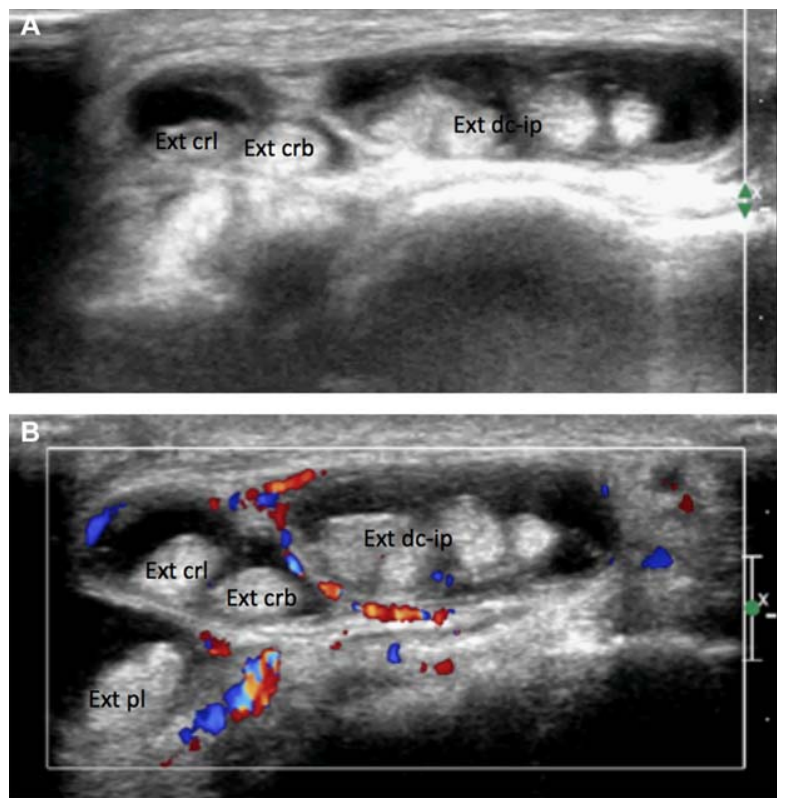
or anechoic masses. ${ }^{23}$ In the case of spreading of an adjacent soft tissue infection, a subcutaneous abscess may be contiguous with the involved tendon and appears as an inhomogeneously hypoechoic fluid collection with irregular margins and peripheral hyperemia on Doppler imaging (Figure 11). ${ }^{17}$ If present, a foreign body is depicted as extraneous material with posterior acoustic shadowing or reverberation artifacts. ${ }^{24}$ Chronically, mycobacterial or fungal tenosynovitis may result in synovial thickening. ${ }^{24}$

\section{Traumatic Tendon Injuries}

\section{Tendon Tears}

Tears of the tendons of hand and wrist include avulsions that involve the tendon distal insertion and, less commonly, midsubstance tears often related to lacerations. ${ }^{25}$ Underlying inflammatory conditions (eg, rheumatoid arthritis) ${ }^{26}$ local steroid injections, ${ }^{27}$ connective tissue disease (eg, Ehlers-Danlos syndrome), ${ }^{28}$ and adjacent orthopedic hardware ${ }^{29}$ represent risk factors for tendon tearing. The clinical presentation reflects the underlying functional deficit and consists of a loss of active motion, even though some degree of compensation may occur (eg, in proximal tears of the middle finger extensor tendon due to the juncturae tendinae) ${ }^{6}$

Tears may be classified as complete or partial tears. Sonographically, complete ruptures present with complete interruption of tendon fiber continuity. Close to the site of injury, the tendon is hyperechoic and thickened, with a loss of the fibrillar echo texture. Widening of the gap between the proximal and distal tendon stumps can be proved by using dynamic maneuvers (Figure 12). ${ }^{30-33}$ Partial tears present with incomplete disruption of tendon fiber continuity and are seen as

Figure 10. Infectious tenosynovitis of the flexor tendons of the little finger. On a longitudinal scan, an intrasynovial effusion (arrowheads) of the flexor digitorum superficialis and profundus tendons (Fle d s-p) is seen and appears lobulated because of the discontinuous array of the digital pulleys.

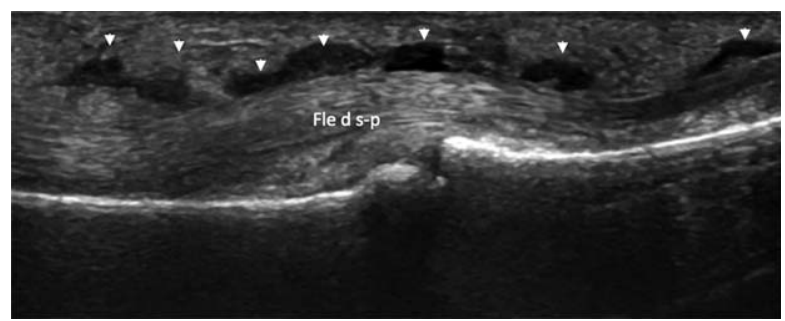

Figure 11. Subcutaneous abscess and septic tenosynovitis. The flexor digitorum superficialis and profundus tendons (Fle d s-p) of the index finger are depicted on B-mode transverse $(\mathbf{A})$ and longitudinal (B) scans; they show some intrasynovial inflammatory fluid and are contiguous with a subcutaneous abscess (arrow and arrowheads), which appears as a hypoechoic area with irregular margins and extends to the tendon sheath. On transverse (C) and longitudinal (D) color Doppler sonograms, peripheral hyperemia of the abscess as well as tendinous and peritendinous hypervascularization are seen.
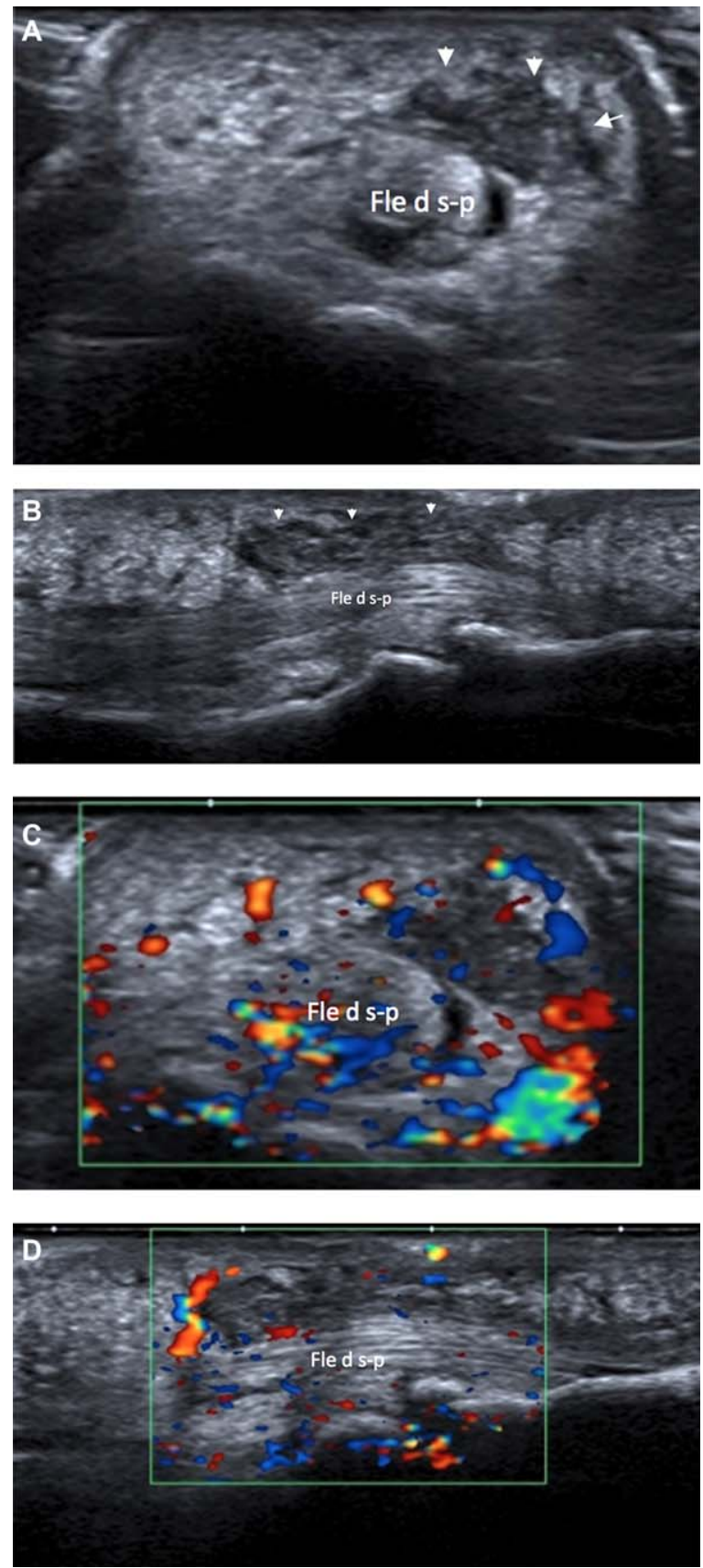
focal hypoechoic defects and tendon thickening at the site of injury (Figure 13). ${ }^{34}$ Hemorrhage is present in cases of acute or subacute tears. There is no evidence of hematoma in the case of chronic injuries. ${ }^{35}$

Importantly, in patients with pain and swelling after trauma to the hand and wrist, occult or undetected fractures should be considered as differential diagnoses and ruled out by sonographic examination. ${ }^{36}$ Undetected fractures may result in hematoma formation and conflict with the digital tendons, thus mimicking a tendon injury (Figure 14). ${ }^{37}$

\section{Mallet Finger}

An avulsion injury may result in a bone fragment detachment, typically found dorsally at the base of the distal phalanx. This condition is known as hammer finger or mallet finger and clinically presents with permanent

Figure 12. Subacute complete tear of the flexor carpi radialis tendon. At the level of the distal radius, transverse $(\mathbf{A})$ and longitudinal (B) sonograms show a large, partially organized hematoma (arrowheads) within the synovial sheath of the flexor carpi radialis tendon, which is completely torn and not seen in its expected anatomic location.
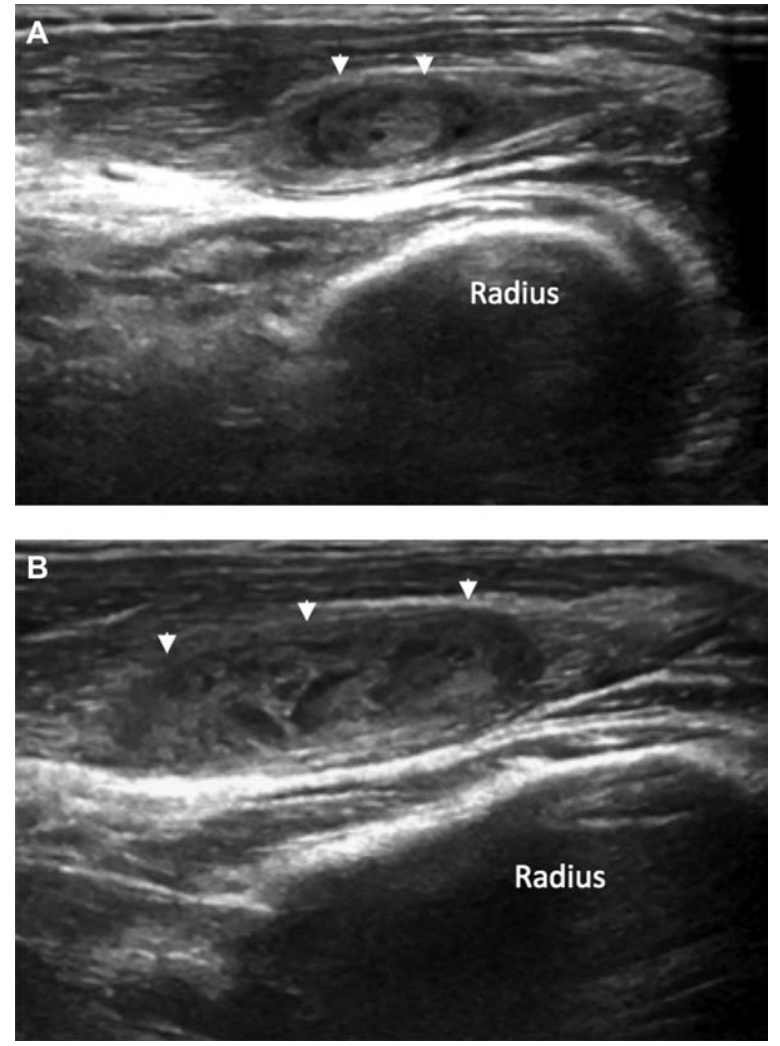

Figure 13. Acute partial tear of the flexor carpi ulnaris tendon. Longitudinal sonogram shows a hypoechoic hematoma (arrowheads) surrounding the flexor carpi ulnaris tendon proximal to its insertion into the pisiform. Close to the hematoma, the tendon shows a focal hypoechoic defect, which indicates a partial tear.

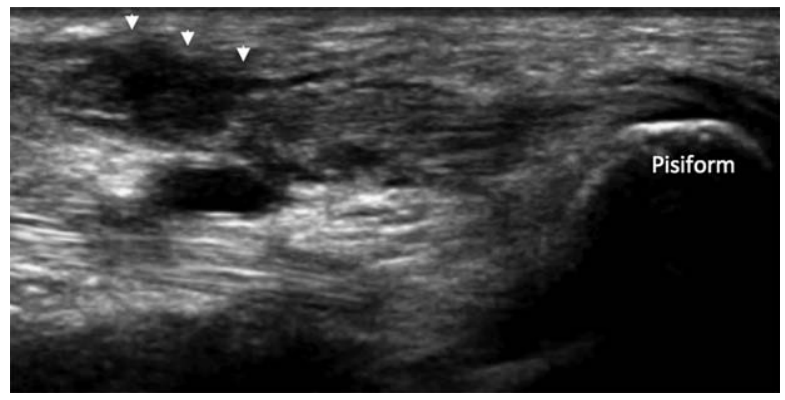

Figure 14. Occult fracture of the third finger. In a patient with digital pain and swelling after trauma, plain radiography (A and $\mathbf{B}$ ) was unremarkable. Longitudinal (C) and transverse (D) sonograms show a fracture of the head of the third metacarpal (arrows) and a hematoma surrounding the site of fracture and resulting in a conflict with the extensor tendon (Ext).
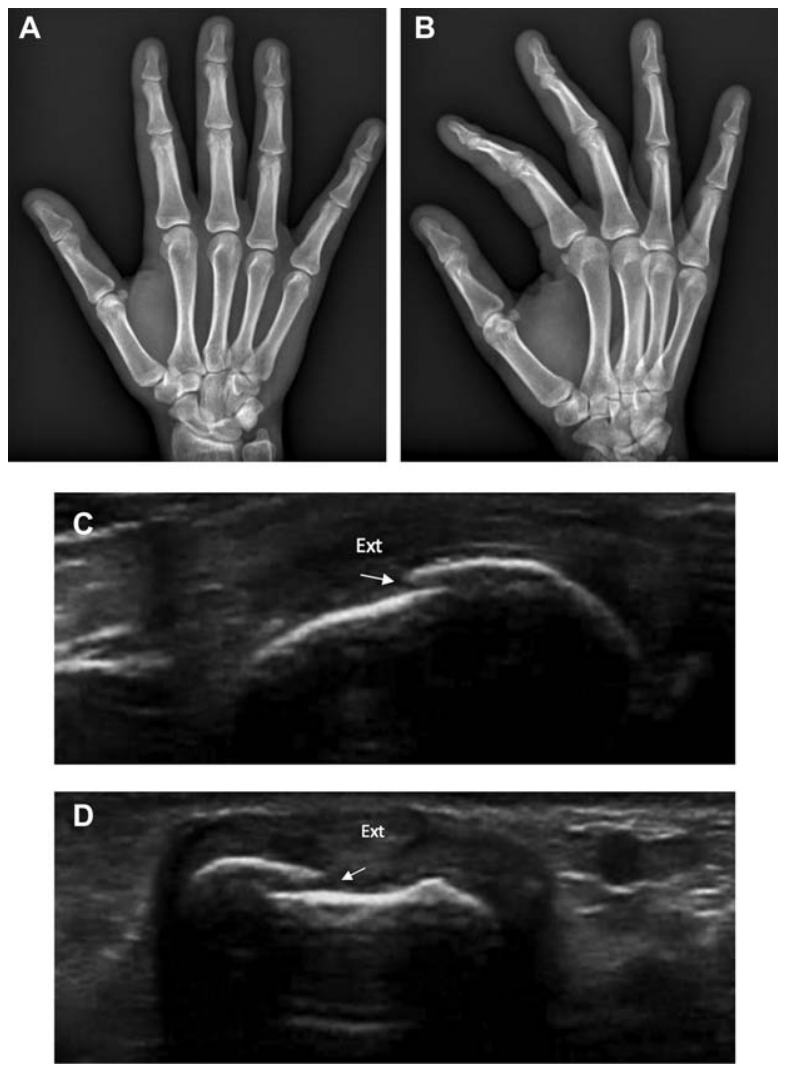
flexion of the distal phalanx. ${ }^{38}$ Sonographic features of mallet finger include a hyperechoic bone fragment with posterior shadowing, partial or complete discontinuity of tendon fibers, lack of movements of the extensor tendon under dynamic assessment, and hematoma at the avulsion site (Figure 15). ${ }^{39}$

\section{Stenosing Tenosynovitis}

Stenosing forms of tenosynovitis affect tendons that, enveloped by their own synovial sheath, run through osteofibrous tunnels. These tunnels are delimited deeply by cortical bone and superficially by a retinaculum or pulley according to their location. Retinaculum or pulley thickening, mainly due to mechanical overuse and repetitive microtrauma, is responsible for narrowing of the osteofibrous tunnel and the following tenosynovitis. Sonographic diagnosis of stenosing tenosynovitis relies on an assessment of retinaculum or pulley thickening and decreased tendon motion under dynamic maneuvers. De Quervain disease and trigger finger represent the main types of stenosing tenosynovitis affecting the wrist and hand. ${ }^{40}$

\section{De Quervain Disease}

De Quervain disease is tenosynovitis of the abductor pollicis longus and extensor pollicis brevis tendons contained within the first dorsal compartment of the wrist (Figure 16). ${ }^{41}$ Risk factors include sport-related or

Figure 15. Mallet finger. Plain radiography $(\mathbf{A})$ and sonography (B) show an avulsion fracture (arrows) involving the base of the distal phalanx, at the tendon distal attachment.
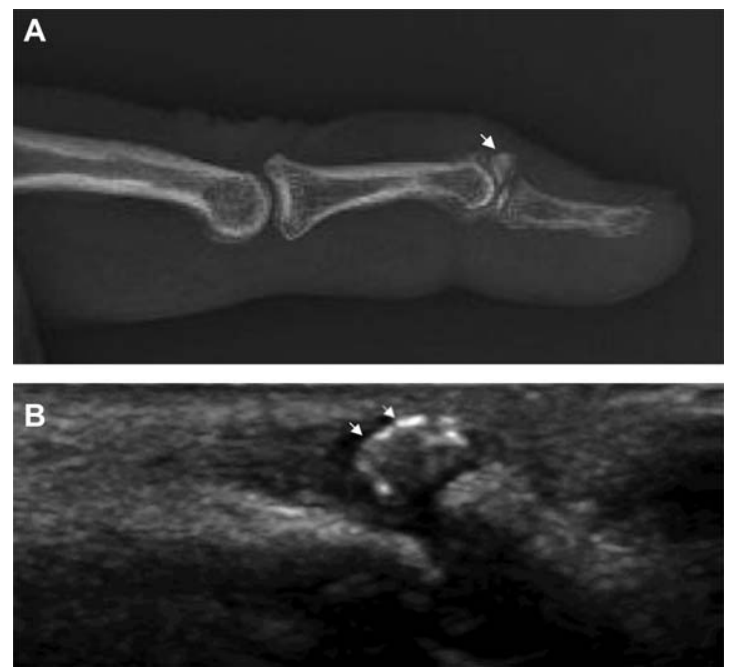

occupational overuse and anatomic variants, such as a longitudinal fibrous septum separating the first compartment into two parts that respectively contain the abductor pollicis longus and extensor pollicis brevis tendons and multiple terminal laminae of the abductor pollicis longus instead of a single distal insertion. ${ }^{42-47}$ Clinically, De Quervain disease usually arises in 30- to 50-year-old individuals and presents with wrist pain at the level of the radial styloid that is evoked or exacerbated by the Finkelstein test. This test consists of an ulnar deviation of the wrist with the thumb flexed into the palm and covered by the remaining digits. ${ }^{41}$

Sonographic features of De Quervain disease include hypoechoic thickening of the extensor retinaculum and enlargement of the abductor pollicis longus and extensor pollicis brevis tendons, which appear rounder than usual on transverse scans. Loss of clear demarcation between these tendons may occur as a result of tendon thickening. Increased vascular flow on Doppler imaging and a variable amount of inflammatory fluid within the synovial sheath are seen in the acute stage of De Quervain disease (Figures 17 and 18); chronically, there may be either little or no intrasynovial fluid. ${ }^{48-50}$ If a complete fibrous septum divides the first dorsal compartment longitudinally into two parts, pathologic changes may be confined to only a single tendon (usually the extensor pollicis brevis tendon), thus requiring the treatment to be targeted accordingly (Figure 19). ${ }^{51,52}$

Figure 16. Schematic diagram of the first dorsal compartment. The tendons of the abductor pollicis longus and extensor pollicis brevis muscles run through the first compartment. These tendons usually share a common synovial sheath, shown here in light blue. The extensor retinaculum (arrowhead) overlies the first compartment and is shown in gray.

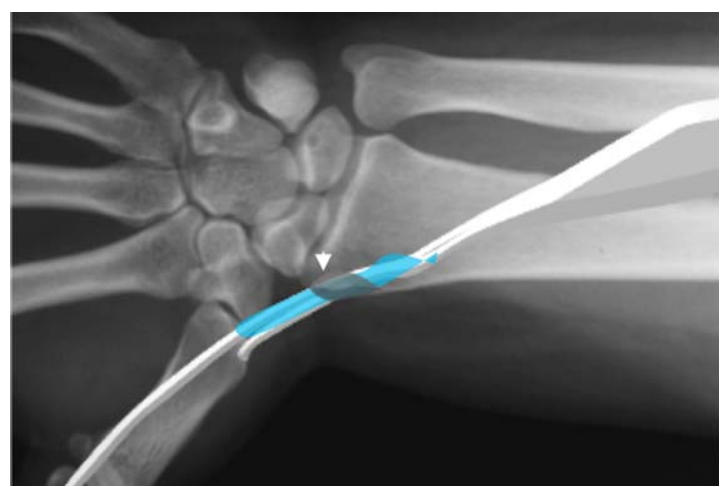




\section{Trigger Finger}

Trigger finger is a common disorder of the hand with a lifetime risk of $2 \%$ to $3 \%$. It is seen more frequently in diabetics and in women, typically in the fifth to sixth decade, and both chronic overuse and local blunt traumas are regarded as etiologic factors. ${ }^{53}$ The clinical presentation includes a painful blockage and triggering of the affected digit from flexion to extension. It mostly involves the metacarpophalangeal joint and is due to thickening of the Al pulley with subsequent restriction of motion of the flexor tendons (Figure 20). The ring finger is most commonly involved, followed by the thumb and middle finger. ${ }^{53}$ Sonographic features of trigger finger include hypoechoic thickening of the Al pulley and flexor tendon tenosynovitis with intrasynovial fluid (Figure 21). ${ }^{54-56}$

\section{Intersection Syndrome}

Intersection syndrome is an uncommon overuse disorder of the dorsal tendons of the wrist and is classified into proximal and distal intersection syndrome. ${ }^{57,58}$

Figure 17. Acute De Quervain disease. Sonography shows thickening of the extensor retinaculum (arrows and arrowhead) and enlargement of the abductor pollicis longus (Abd pl) and extensor pollicis brevis (Ext pb) tendons with loss of clear demarcation between them (A). A large amount of fluid is seen within their common synovial sheath (B).
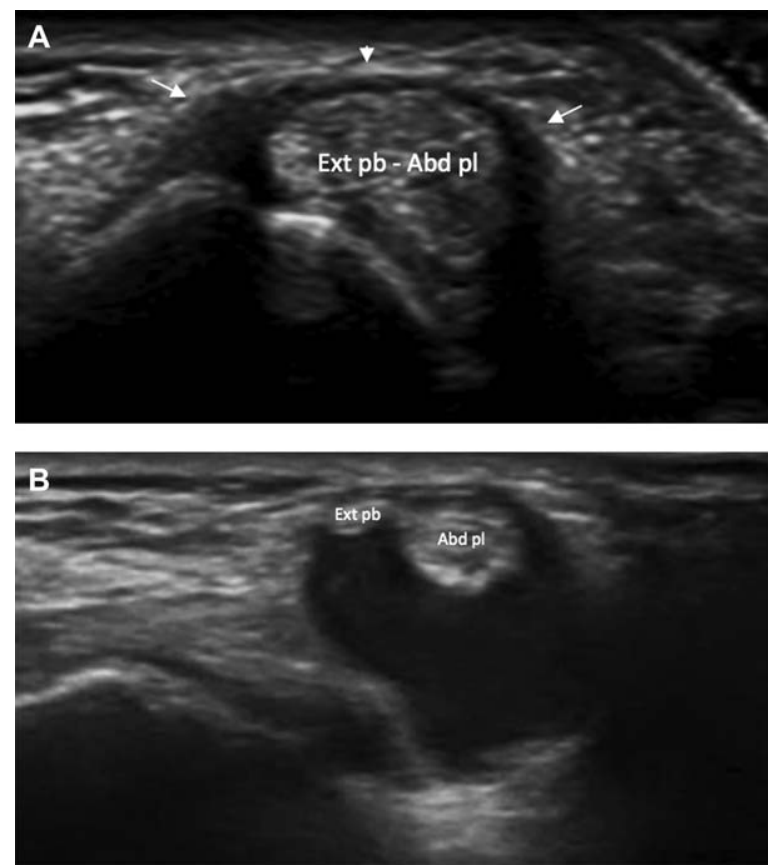

Figure 18. Acute De Quervain disease. Sonography shows thickening of the extensor retinaculum (arrowheads), enlargement of the abductor pollicis longus (Abd $\mathrm{pl}$ ) and extensor pollicis brevis (Ext $\mathrm{pb}$ ) tendons, and intrasynovial fluid (A). Two anatomic variations occur: a distal split of the synovial sheath into two sheaths, one for each tendon, and multiple terminal laminae of the abductor pollicis longus tendon (B).
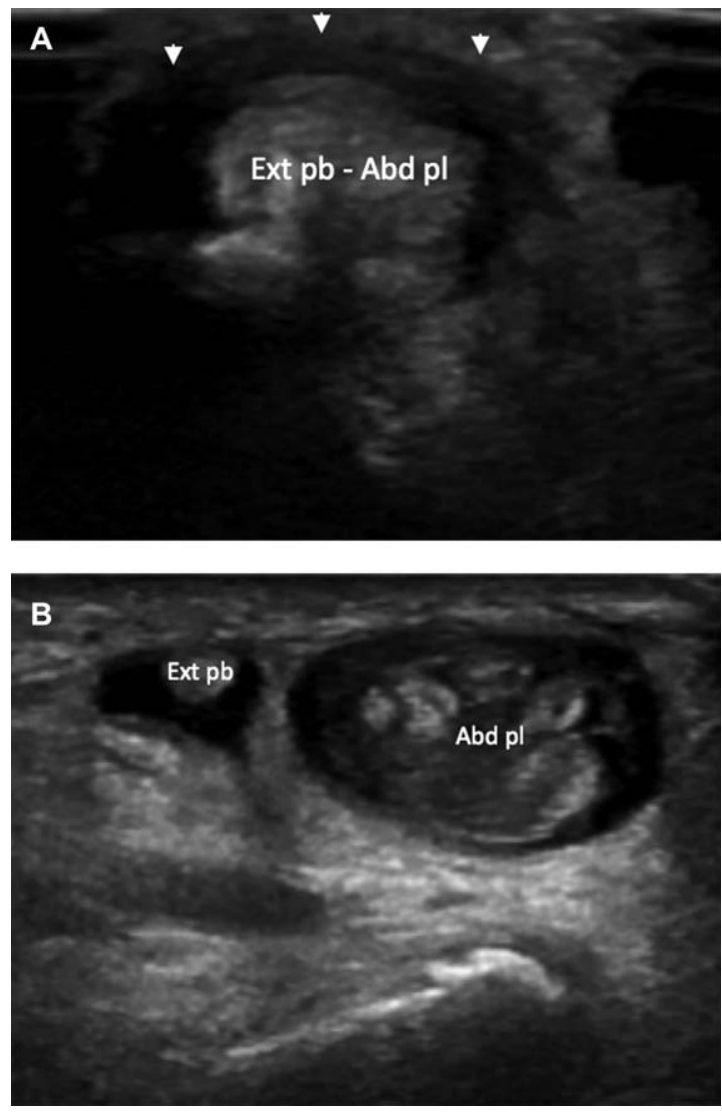

Figure 19. Acute De Quervain disease. A vertical fibrous septum (arrows) divides the first dorsal compartment into two parts, which contain the abductor pollicis longus (Abd pl) and extensor pollicis brevis (Ext pb) tendons, respectively. Pathologic changes with intrasynovial fluid are confined to the extensor pollicis brevis tendon.

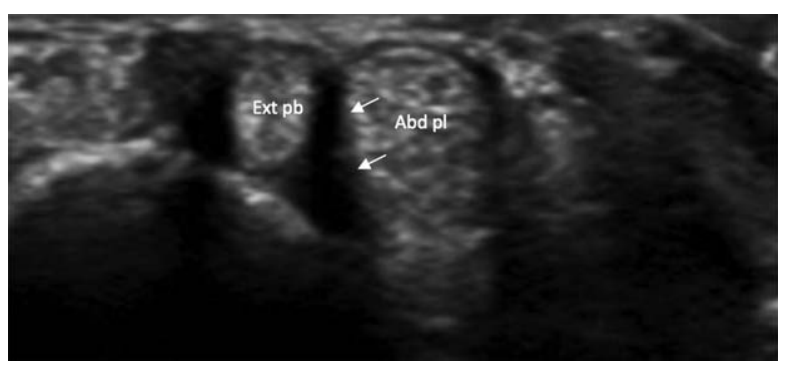


Proximal intersection syndrome develops in a friction site located 3.5 to $4.8 \mathrm{~cm}$ proximal to the Lister tubercle, where the tendons of the second compartment run beneath those of the first compartment. ${ }^{59}$ Distal intersection syndrome is rarer and develops in a further friction site located just beyond the Lister tubercle, where the third dorsal compartment tendon crosses over those of the second compartment (Figure 22).$^{60}$ Risk factors

Figure 20. Schematic diagram of the A1 pulley and digital flexor tendons. The A1 pulley (arrowhead), shown here in gray, is located on the volar aspect of the metacarpophalangeal joint and stabilizes the deep and superficial digital flexor tendons.

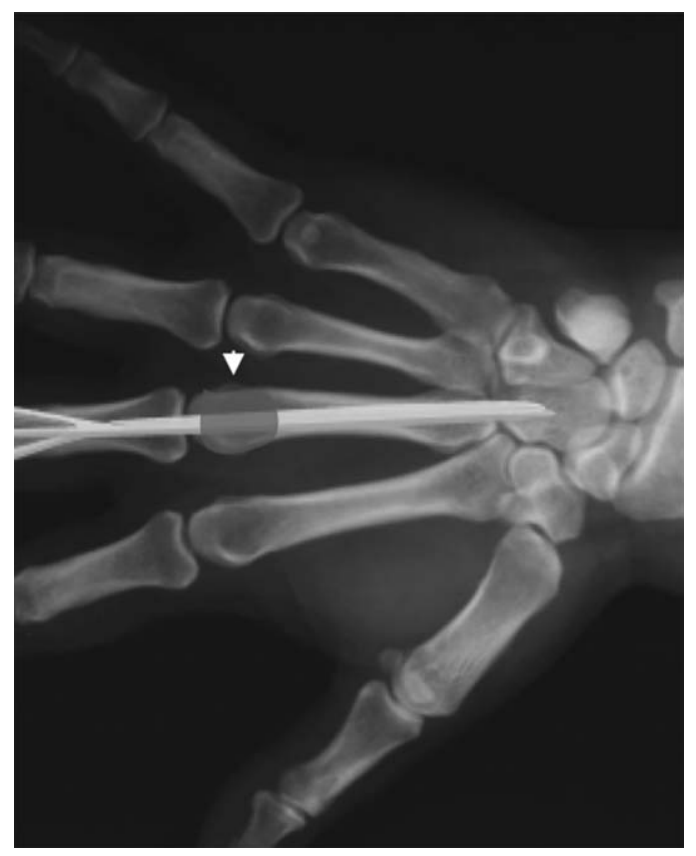

Figure 21. Trigger finger. Sonography shows hypoechoic thickening of the A1 pulley (arrows) and moderate tenosynovitis of the flexor digitorum superficialis and profundus (Fle $d s-p$ ) tendons of the middle finger. Normal A1 pulley of the ring finger and the volar plates $(\mathrm{V} p)$ are also shown.

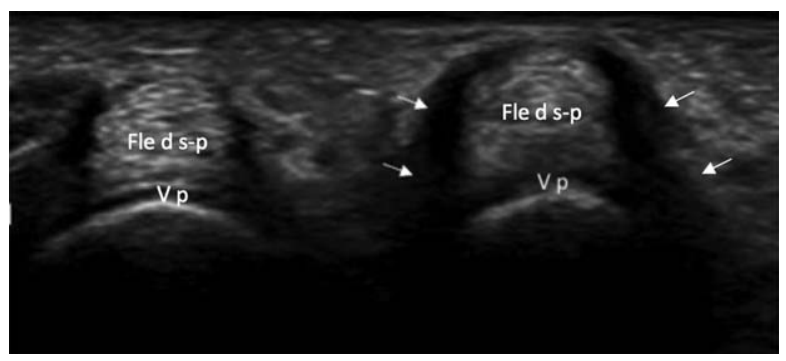

comprise trauma and repetitive stress at the wrist during occupational duties or sport activities, such as rowing and weightlifting. ${ }^{25}$ The clinical presentation resembles that of De Quervain disease and includes pain, swelling, and an audible crepitus related to wrist motion at the level of distal radial epiphysis. ${ }^{61}$

The main sonographic feature of proximal intersection syndrome is an effusion within the synovial sheath of the second dorsal compartment of the wrist, variably

Figure 22. Schematic diagram of the proximal and distal intersection sites. The proximal intersection site (arrowhead) is located 3.5 to $4.8 \mathrm{~cm}$ proximal to the Lister tubercle, where the tendons of the second compartment run beneath those of the first compartment. The distal intersection site (arrow) is located just beyond the Lister tubercle, where the tendon of the third dorsal compartment crosses over those of the second compartment. Tendon synovial sheaths are shown here in light blue.

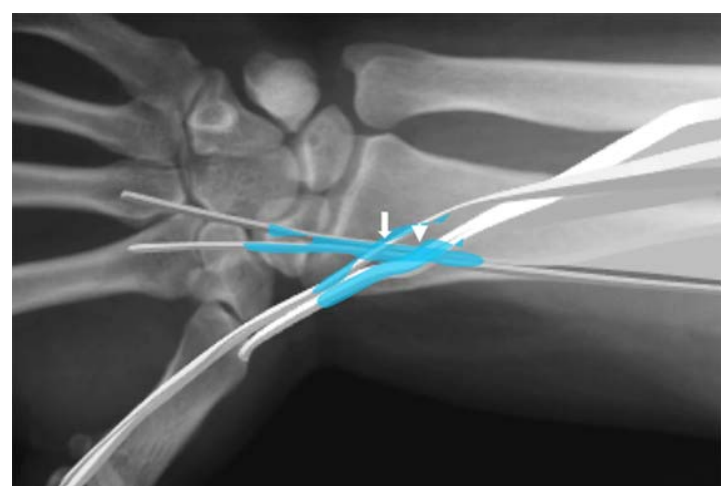

Figure 23. Proximal intersection syndrome. Sonography shows an intrasynovial effusion within the second dorsal compartment containing the extensor carpi radialis longus (Ext crl) and brevis (Ext crb) tendons.

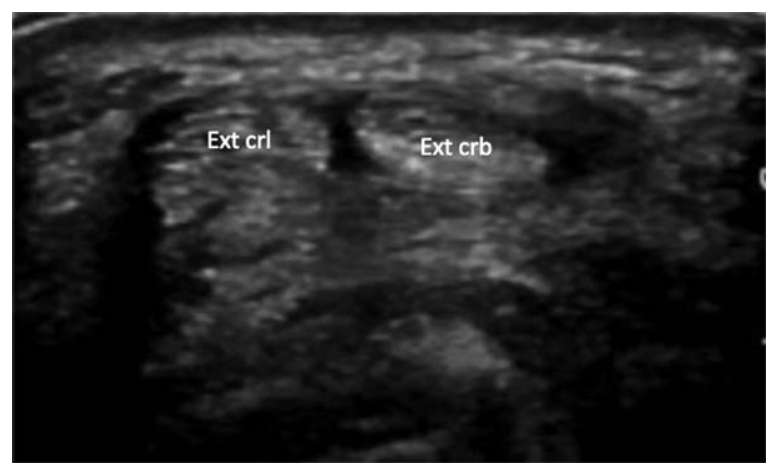


located between the proximal and distal intersections; occasionally, some amounts of inflammatory fluid may be found within the synovial sheath of the first dorsal compartment (Figure 23). ${ }^{62,63}$ If each tendon of the second compartment has its own synovial sheath as an anatomic variant, inflammatory changes may be confined to only a single tendon, usually that of the extensor carpi radialis brevis. ${ }^{43}$ Tendon thickening may occur at the proximal intersection site. ${ }^{64}$ Sonographically, distal intersection syndrome presents with an effusion within the synovial sheaths of the second and third dorsal compartments, usually distal to the distal intersection site. ${ }^{62}$ In both proximal and distal intersection syndromes, sonography may show soft tissue edema or an adventitial bursitis between the two groups of affected tendons. ${ }^{62,63}$ Increased vascularization may be seen on Doppler imaging. ${ }^{25}$

\section{Insertional Tendinopathy}

Among the tendons of the hand and wrist, insertional tendinopathy most commonly affects the flexor carpi ulnaris tendon at or near its attachment to the pisiform (Figure 24). ${ }^{65}$ Repetitive microtrauma is responsible for collagen fiber degeneration and compensative repair processes, finally resulting in tendon weakening and an increased risk of rupture. ${ }^{66}$ The clinical presentation includes pain and tenderness 2 to $3 \mathrm{~cm}$ proximal to the flexor carpi ulnaris insertion into the pisiform. ${ }^{65}$

Sonography shows tendon enlargement and a hypoechoic or anechoic appearance with loss of the fibrillar pattern. Entheseal calcification as well as erosive cortical

Figure 24. Schematic diagram of the flexor carpi ulnaris. The flexor carpi ulnaris, shown here in gray, belongs to the most superficial myotendinous layer of the anterior forearm and is located medially. Its tendon fibers insert into the pisiform, the flexor retinaculum, the hook of the hamate, and the base of the fifth metacarpal.

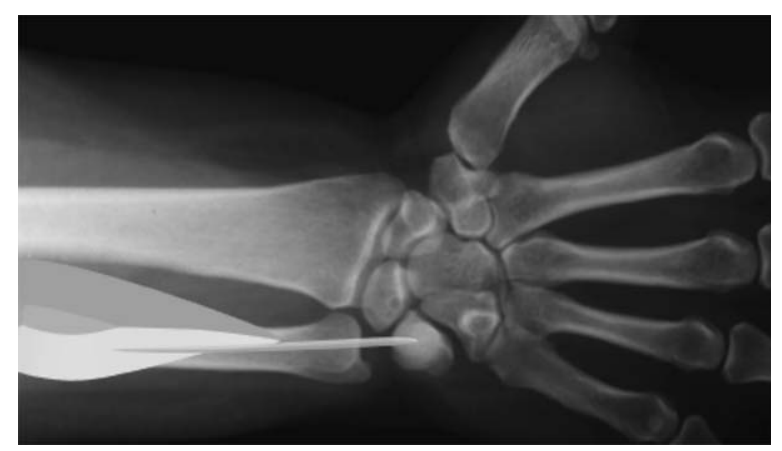

irregularities of the pisiform may develop. Increased peritendinous and intratendinous vascularization on Doppler imaging may also be seen and correlates with symptoms (Figure 25). ${ }^{67}$

\section{Tendinous Instability}

This peculiar group comprises a series of pathologic conditions in which some of the stabilizing mechanisms of the involved tendon are damaged, thus causing tendon subluxation or dislocation. ${ }^{37}$ The etiology may be either traumatic or, less commonly, related to congenital laxity. ${ }^{17}$

Figure 25. Enthesopathy of the flexor carpi ulnaris tendon. Longitudinal (A) and transverse (B) sonograms show tendon enlargement, a hypoechoic appearance with loss of the fibrillar pattern, and entheseal calcifications (arrowheads). On Doppler imaging, increased vascularization is seen (C).
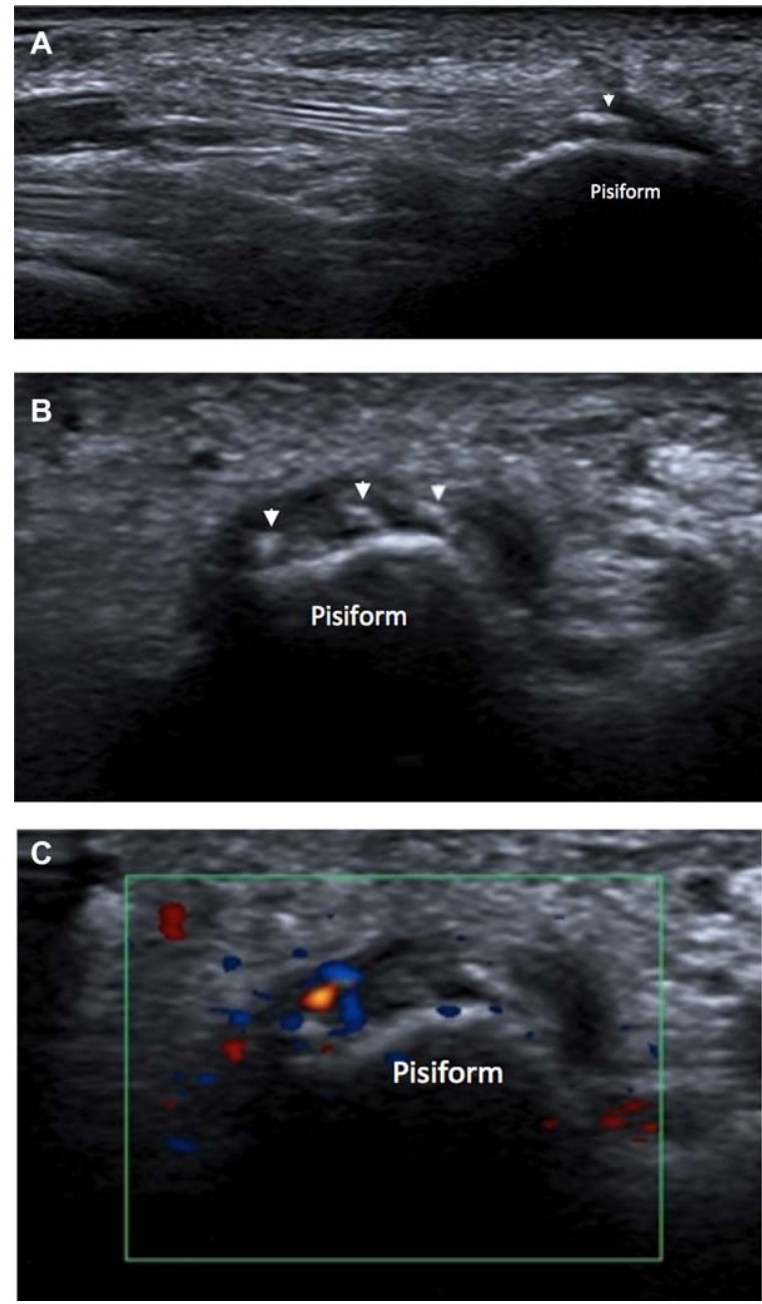


\section{Extensor Carpi Ulnaris Instability}

Extensor carpi ulnaris instability includes a spectrum of disorders ranging from minor subluxation to frank dislocation of the extensor carpi ulnaris tendon during wrist movements. It has been described in athletes such as tennis players, ${ }^{68,69}$ in rheumatoid patients, ${ }^{70}$ and in asymptomatic individuals. ${ }^{71}$ Within the sixth dorsal compartment, the extensor carpi ulnaris tendon is held in place by an overlying synovial subsheath that is located beneath the extensor retinaculum. ${ }^{72}$ Even though the extensor retinaculum is intact, injury of this subsheath causes the extensor carpi ulnaris tendon to repeatedly dislocate in the ulnar direction. It clinically presents with pain and audible snapping of the tendon in ulnar deviation or supination. ${ }^{73-75}$ A dynamic sonographic assessment allows for the identification of subluxationdislocation of the extensor carpi ulnaris tendon as well as associated tears (Figure 26). ${ }^{76-78}$

Figure 26. Extensor carpi ulnaris instability in a rheumatoid patient. Transverse sonograms show the extensor carpi ulnaris tendon (Ext $\mathrm{Cu}$ ), which dislocates out of the ulnar groove and in the ulnar direction during wrist supination (A) and ulnar deviation (B).
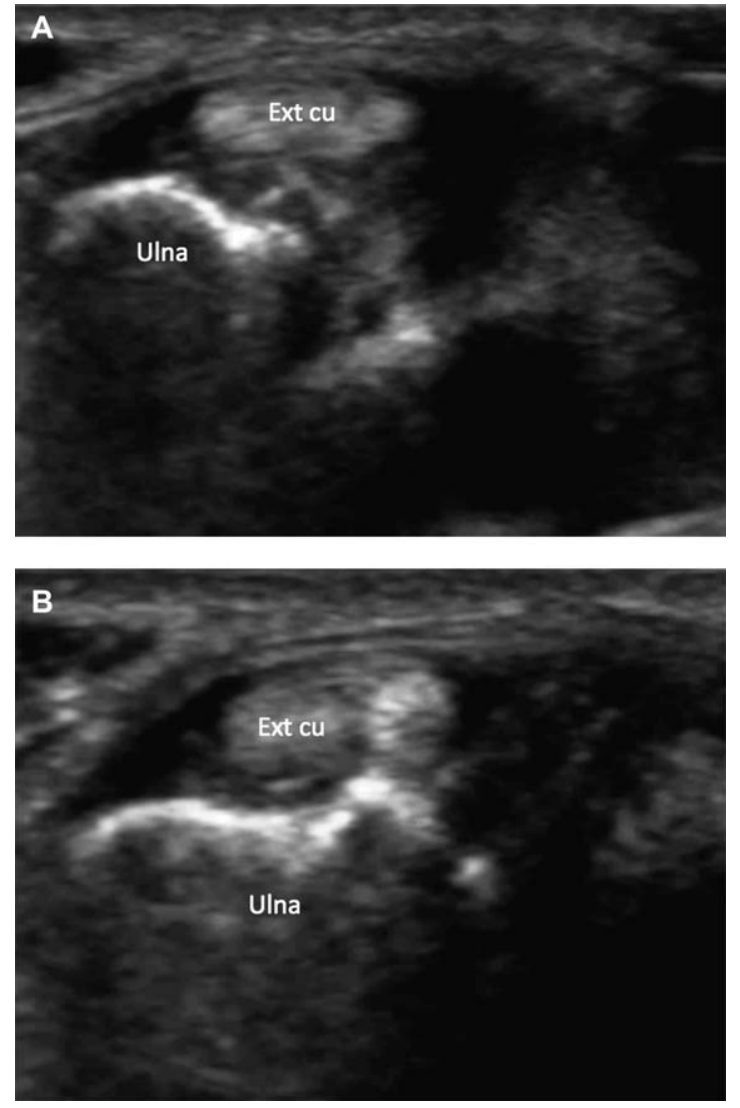

\section{Climber Finger}

Acute tears of annular pulleys are frequently related to sport activities, specifically rock climbing, and mostly involve the middle and ring fingers. ${ }^{79}$ Patients present with pain and swelling over the affected pulley and may have a "pop" at the time of injury. ${ }^{80}$ Sonographic findings include variable degrees of anterior subluxation of the digital flexor tendons that are no longer in contact with the bony surface and, in the acute stage, a hematoma within the tendon sheath. Anterior instability increases if the affected finger is flexed against resistance. Ruptured pulleys are usually not seen on sonography. ${ }^{81-83}$ A lobulated hematic effusion should be distinguished from articular ganglia arising at the level of the pulleys under a dynamic sonographic assessment. ${ }^{84}$

\section{Boxer Knuckle}

Boxer knuckle is an uncommon injury to the sagittal bands that stabilize the extensor tendons at the dorsal aspect of metacarpal heads. ${ }^{85}$ It typically occurs in boxers, mostly affecting the middle finger, and clinically presents with pain, swelling, loss of full extension, and either ulnar or radial snapping subluxation of the extensor tendon. ${ }^{86,87}$ Sonography reveals tendon subluxation contralateral to the torn sagittal band under a dynamic examination: the involved tendon dislocates when the patient is asked to make a fist and returns to its normal position during finger extension. 88,89

\section{Tendinopathy in Inflammatory Rheumatic Diseases}

Rheumatoid arthritis and psoriatic arthritis represent the two most common inflammatory rheumatic diseases affecting the tendons of the hand and wrist. ${ }^{90}$ Rarely, systemic sclerosis may be responsible for tenosynovitis and tendon tearing. Systemic lupus erythematosus may produce tendon rupture. $^{91}$

Rheumatoid arthritis affects up to $1 \%$ of the general population, often involves the hand and wrist, and is typically symmetric. ${ }^{92}$ The main site of inflammation is the synovial membrane, which becomes abnormally thickened, thus forming the so-called synovial pannus. ${ }^{93}$ Synovitis involves not only joints but also tendon sheaths, and it may result in structural articular and periarticular damage in the long term. ${ }^{94,95}$ Tenosynovitis of the hand and wrist has been estimated to develop in up to $95 \%$ of patients with rheumatoid arthritis and most often affects 
the extensor carpi ulnaris tendon. ${ }^{96}$ Sonographic findings of rheumatoid tenosynovitis include thickening of the tendon sheath, intrasynovial fluid, and alterations in the tendon echo texture ranging from diffuse blurring to focal defects. ${ }^{97-99}$ Doppler imaging reveals synovial hyperemia as a sign of active inflammation; a decrease in synovial vascularization indicates fibrous pannus formation as well as a good response to treatment (Figure 27). ${ }^{100,101}$ Complete and partial tears of the hand and

Figure 27. Extensor carpi ulnaris tenosynovitis in a rheumatoid patient. Transverse (A) and longitudinal (B) B-mode sonograms depict the extensor carpi ulnaris tendon (Ext $\mathrm{Cu}$ ) within the sixth dorsal compartment; synovial thickening and bone erosions of the ulnar styloid process (arrow) are seen. Transverse (C) and longitudinal (D) Doppler sonograms reveal marked hyperemia, which indicates active inflammation.
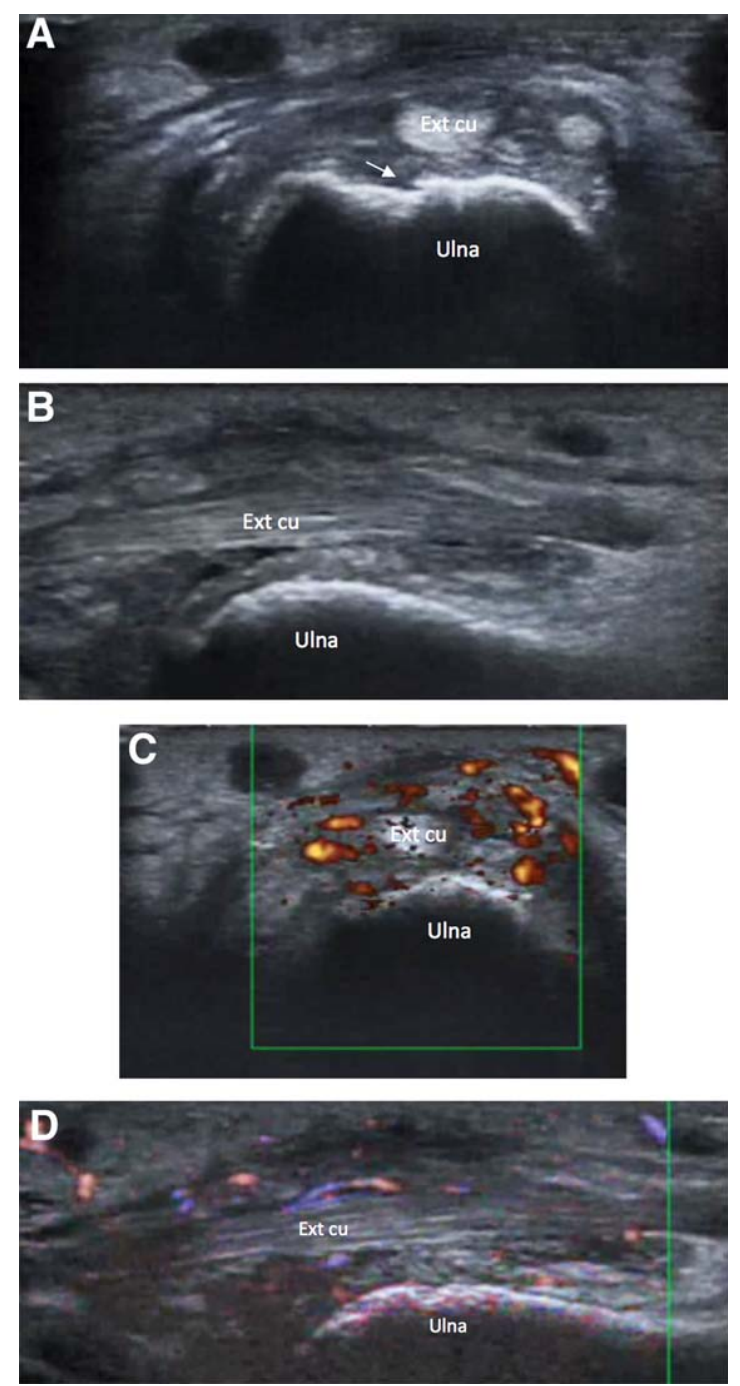

wrist tendons have been reported in $1 \%$ of patients with rheumatoid arthritis, specifically in cases of advanced disease. ${ }^{96}$ The most common sites of tendon rupture in rheumatoid wrists are the extensor pollicis longus and extensor digiti minimi proprius tendons. ${ }^{91}$ Finally, subluxation-dislocation of the extensor carpi ulnaris tendon may develop in rheumatoid patients (Figure 26). ${ }^{70}$

Psoriatic arthritis presents with asymmetric joint involvement, predominating in the distal interphalangeal joints. Dactylitis develops in up to $40 \%$ of patients and is characterized by subcutaneous tissue swelling and tenosynovitis of the flexor tendons. ${ }^{102-104}$ Extensor tenosynovitis as well as enthesopathy of the flexor and extensor tendons may also be found. ${ }^{105-107}$

\section{Postsurgical Examination}

\section{Operated Tendon Appearance: Healthy and Pathologic}

Sonography has been proven to be effective in evaluating tendon integrity and detecting complications after surgical repair. However, the postintervention tendon

Figure 28. Operated tendon. In the first few months after surgical repair, on longitudinal $(\mathbf{A})$ and transverse $(\mathbf{B})$ B-mode scans, the healthy extensor pollicis longus tendon (Ext pl) is thickened and shows a heterogeneous echo texture with loss of the fibrillar pattern and fine intratendinous calcifications. Doppler imaging (C) shows intratendinous hyperemia.
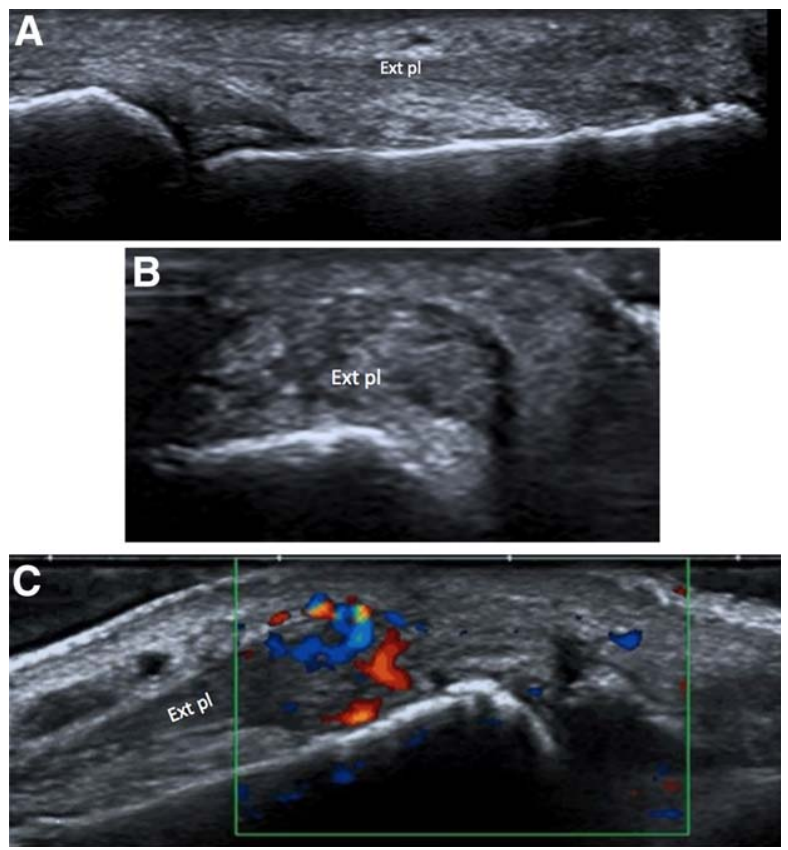
appearance differs from that of a healthy nonoperated tendon in several characteristics; thus, knowledge of the normal and pathologic sonographic features after surgery as well as the surgical technique used is required. ${ }^{108}$ Healthy repaired tendons are larger and wider than nonoperated ones and show an inhomogeneous echo texture with a loss of the fibrillar pattern and irregular contours (Figure 28). The surgical material can be found in the context of the tendon. Tendon gliding is physiologically reduced under a dynamic examination. Large fluid collections as well as extensive calcifications should instead be considered pathologic findings. Doppler imaging shows no vascularization in the immediate postoperative period. Intratendinous vascularization physiologically increases in the first 3 months after surgery and then stabilizes and finally regresses within 6 months
(Figure 28). Beyond the first 6 months, persistent hypervascularization is pathologic. ${ }^{108,109}$ The main postsurgical complications include rerupture, adhesions, and lengthening of the tendon callus that results from healing process. 108

\section{Orthopedic Hardware Impingement}

As the tendons of the hand and wrist are in close contact with the bone plane, specifically within their osteofibrous tunnels, during muscle contraction, they may conflict with orthopedic hardware positioned in several surgical interventions. The risk of impingement varies according to the site and nature of the surgical procedure. ${ }^{29}$ If the patient has local pain, pressure should be exerted with the transducer to reproduce the described symptoms under sonographic monitoring. ${ }^{10}$ Tenosynovitis and

Figure 29. Orthopedic hardware impingement. Plain radiography (A and $\mathbf{B})$ shows a distal radial fracture fixed with a plate and screws. Transverse (C) and longitudinal (D) sonograms show screw impingement on the myotendinous junction of the abductor pollicis longus and extensor pollicis brevis at the dorsal radius. The orthopedic hardware appears hyperechoic with a posterior reverberation artifact. In a case of impingement, orthopedic hardware removal is indicated (E and $\mathbf{F})$.
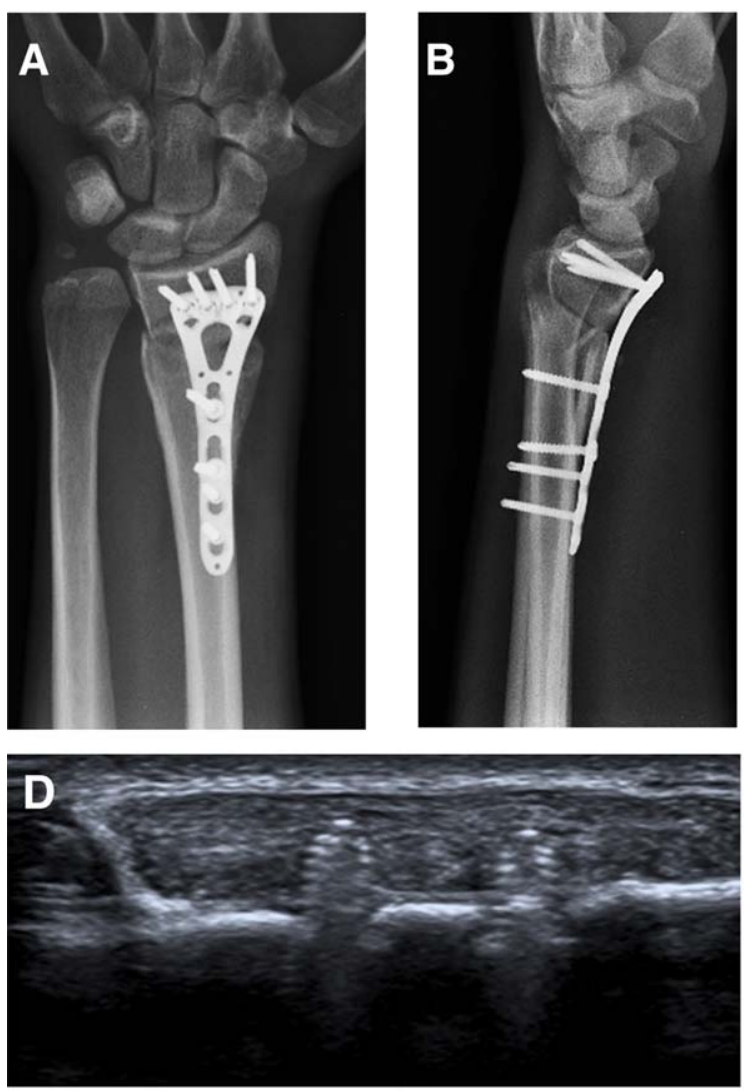
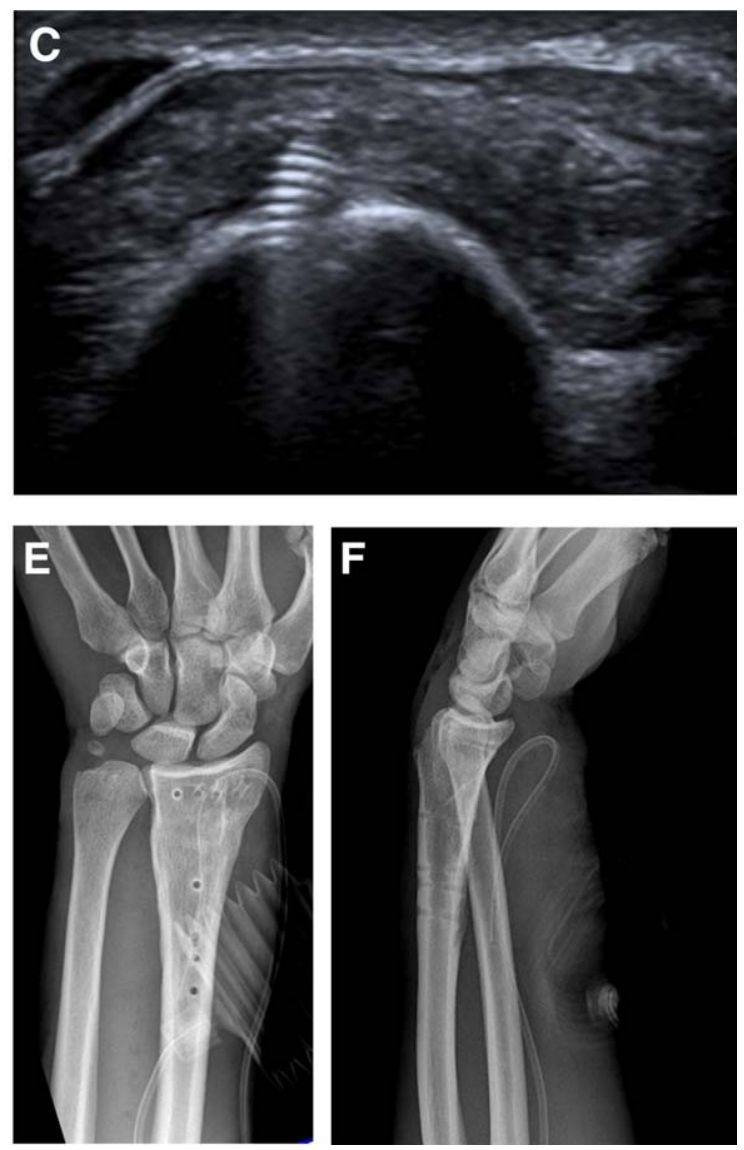
local hypervascularization on Doppler imaging are common sonographic findings of impingement. The orthopedic hardware typically appears hyperechoic with a posterior reverberation artifact (Figure 29). A persistent conflict may result in partial tearing and finally complete rupturing of the involved tendon. Inflammation of a preexisting bursa or an adventitial bursitis may also develop. A local entrapment should be excluded both clinically and sonographically. ${ }^{10,111}$

\section{Conclusions}

A variety of tendon disorders affecting the hand and wrist are commonly encountered in daily clinical practice. Knowledge of the medical history as well as symptoms and signs is basic for a correct diagnostic approach. However, the clinical presentations are often similar, and imaging is required to narrow down the list of differential diagnoses. Sonography is effective in assessing the tendons of the hand and wrist and related disorders, thus representing a valuable tool to ensure appropriate management and limit functional impairment.

\section{References}

1. Barr AE, Barbe MF, Clark BD. Work-related musculoskeletal disorders of the hand and wrist: epidemiology, pathophysiology, and sensorimotor changes. J Orthop Sports Phys Ther 2004; 34:610-627.

2. Bodor M, Fullerton B. Ultrasonography of the hand, wrist, and elbow. Phys Med Rehabil Clin N Am 2010; 21:509-531.

3. Olubaniyi BO, Bhatnagar G, Vardhanabhuti V, Brown SE, Gafoor A, Suresh PS. Comprehensive musculoskeletal sonographic evaluation of the hand and wrist. J Ultrasound Med 2013; 32:901-914.

4. Gitto S, Draghi F. Normal sonographic anatomy of the wrist with emphasis on assessment of tendons, nerves, and ligaments. J Ultrasound Med 2016; 35:1081-1094.

5. Lee JC, Healy JC. Normal sonographic anatomy of the wrist and hand. Radiographics 2005; 25:1577-1590.

6. Standring S. Wrist and hand. In: Standring S (ed). Gray's Anatomy: The Anatomical Basis of Clinical Practice. 40th ed. London, England: Churchill Livingstone; 2008:857-898.

7. Clavero JA, Golano P, Farinas O, Alomar X, Monill JM, Esplugas M. Extensor mechanism of the fingers: MR imaging-anatomic correlation. Radiographics 2003; 23:593-611.

8. Sookur PA, Naraghi AM, Bleakney RR, Jalan R, Chan O, White LM. Accessory muscles: anatomy, symptoms, and radiologic evaluation. Radiographics 2008; 28:481-499.
9. Presazzi A, Bortolotto C, Zacchino M, Madonia L, Draghi F. Carpal tunnel: normal anatomy, anatomical variants and ultrasound technique. J Ultrasound 2011; 14:40-46.

10. Schmidt HM. The "loge de Guyon": a contribution to the clinical anatomy of the human hand. Acta Anat 1988; 131:113-121.

11. Hauger O, Chung CB, Lektrakul N, et al. Pulley system in the fingers: normal anatomy and simulated lesions in cadavers at MR imaging, CT, and US with and without contrast material distention of the tendon sheath. Radiology 2000; 217:201-212.

12. De Maeseneer M, Marcelis S, Jager T, Lenchik L, Pouders C, Van Roy P. Sonography of the finger flexor and extensor system at the hand and wrist level: findings in volunteers and anatomical correlation in cadavers. Eur Radiol 2008; 18:600-607.

13. Gitto S, Messina C, Mauri G, Aliprandi A, Sardanelli F, Sconfienza LM. Dynamic high-resolution ultrasound of intrinsic and extrinsic ligaments of the wrist: how to make it simple. Eur J Radiol 2017; 87: $20-35$.

14. Martinoli C, Bianchi S, Dahmane M, Pugliese F, Bianchi-Zamorani MP, Valle M. Ultrasound of tendons and nerves. Eur Radiol 2002; 12:44-55.

15. Allison SJ. Musculoskeletal ultrasound: evaluation of the finger. AJR Am J Roentgenol 2011;196:W308.

16. Bianchi S, Martinoli C, de Gautard R, Gaignot C. Ultrasound of the digital flexor system: normal and pathological findings. J Ultrasound 2007; 10:85-92.

17. Draghi F. Ultrasonography of the Upper Extremity: Hand and Wrist. Cham, Switzerland: Springer; 2014.

18. Patel DB, Emmanuel NB, Stevanovic MV, et al. Hand infections: anatomy, types and spread of infection, imaging findings, and treatment options. Radiographics 2014; 34:1968-1986.

19. McDonald LS, Bavaro MF, Hofmeister EP, Kroonen LT. Hand infections. J Hand Surg Am 2011; 36:1403-1412.

20. Chau CL, Griffith JF. Musculoskeletal infections: ultrasound appearances. Clin Radiol 2005; 60:149-159.

21. Reinus WR, De Cotiis D, Schaffer A. Changing patterns of septic tenosynovitis of the distal extremities. Emerg Radiol 2015; 22:133-139.

22. Turecki MB, Taljanovic MS, Stubbs AY, et al. Imaging of musculoskeletal soft tissue infections. Skeletal Radiol 2010; 39:957-971.

23. Chau CL, Griffith JF, Chan PT, Lui TH, Yu KS, Ngai WK. Ricebody formation in atypical mycobacterial tenosynovitis and bursitis: findings on sonography and MR imaging. AJR Am J Roentgenol 2003; 180:1455-1459.

24. Teefey SA, Middleton WD, Boyer MI. Sonography of the hand and wrist. Semin Ultrasound CT MR 2000; 21:192-204.

25. Plotkin B, Sampath SC, Sampath SC, Motamedi K. MR Imaging and US of the wrist tendons. Radiographics 2016; 36:1688-1700.

26. Bortolotto C, Draghi F. Rupture of the sheath of the extensor carpi ulnaris tendon in a patient affected by rheumatoid arthritis. JUltrasound 2016; 19:77-79. 
27. Mills SP, Charalambous CP, Hayton MJ. Bilateral rupture of the extensor pollicis longus tendon in a professional goalkeeper following steroid injections for extensor tenosynovitis. Hand Surg 2009; 14: 135-137.

28. Dowlen H, Roberton BJ, Owers K. Bilateral sequential closed traumatic wrist flexor tendon ruptures. J Hand Surg Eur Vol 2012; 37: 694-695.

29. Bianchi S, van Aaken J, Glauser T, Martinoli C, Beaulieu JY, Della Santa D. Screw impingement on the extensor tendons in distal radius fractures treated by volar plating: sonographic appearance. AJR Am J Roentgenol 2008; 191:W199-W203.

30. De Maeseneer M, Marcelis S, Osteaux M, Jager T, Machiels F, Van Roy P. Sonography of a rupture of the tendon of the extensor pollicis longus muscle: initial clinical experience and correlation with findings at cadaveric dissection. AJR Am J Roentgenol 2005; 184:175-179.

31. Dezfuli B, Taljanovic MS, Melville DM, Krupinski EA, Sheppard JE. Accuracy of high-resolution ultrasonography in the detection of extensor tendon lacerations. Ann Plast Surg 2016; 76:187-192.

32. Lee DH, Robbin ML, Galliott R, Graveman VA. Ultrasound evaluation of flexor tendon lacerations. J Hand Surg Am 2000; 25:236241.

33. Moschilla G, Breidahl W. Sonography of the finger. AJR Am J Roentgenol 2002; 178:1451-1457.

34. Santiago FR, Plazas PG, Fernandez JM. Sonography findings in tears of the extensor pollicis longus tendon and correlation with CT, MRI and surgical findings. Eur J Radiol 2008; 66:112-116.

35. Draghi F, Bianchi S, Gervasio A, Fachinetti C, Gaignot C, de Gautard R. Ultrasound of traumatic disorders of wrist and hand. J Ultrasound 2006; 9:218-226.

36. Cho KH, Lee SM, Lee YH, Suh KJ. Ultrasound diagnosis of either an occult or missed fracture of an extremity in pediatric-aged children. Korean J Radiol 2010; 11:84-94.

37. Fantino O, Borne J, Bordet B. Conflicts, snapping and instability of the tendons: pictorial essay. J Ultrasound 2012; 15:42-49.

38. Bendre AA, Hartigan BJ, Kalainov DM. Mallet finger. J Am Acad Orthop Surg 2005; 13:336-344.

39. Kleinbaum Y, Heyman Z, Ganel A, Blankstein A. Sonographic imaging of mallet finger. Ultraschall Med 2005; 26:223-226.

40. Vuillemin V, Guerini H, Bard H, Morvan G. Stenosing tenosynovitis. J Ultrasound 2012; 15:20-28.

41. Ilyas AM, Ast M, Schaffer AA, Thoder J. De Quervain tenosynovitis of the wrist. J Am Acad Orthop Surg 2007; 15:757-764.

42. Choi SJ, Ahn JH, Lee YJ, et al. de Quervain disease: US identification of anatomic variations in the first extensor compartment with an emphasis on subcompartmentalization. Radiology 2011; 260: 480-486.

43. Draghi F, Bortolotto C, Draghi AG, Gregoli B. Musculoskeletal sonography for evaluation of anatomic variations of extensor tendon synovial sheaths in the wrist. J Ultrasound Med 2015; 34:1445-1452.
44. Kwon BC, Choi SJ, Koh SH, Shin DJ, Baek GH. Sonographic Identification of the intracompartmental septum in de Quervain's disease. Clin Orthop Relat Res 2010; 468:2129-2134.

45. Nagaoka M, Matsuzaki H, Suzuki T. Ultrasonographic examination of de Quervain's disease. J Orthop Sci 2000; 5:96-99.

46. Rousset P, Vuillemin-Bodaghi V, Laredo JD, Parlier-Cuau C. Anatomic variations in the first extensor compartment of the wrist: accuracy of US. Radiology 2010; 257:427-433.

47. Sato J, Ishii Y, Noguchi H. Ultrasonographic evaluation of the prevalence of an intracompartmental septum in patients with de Quervain's disease. Orthopedics 2016; 39:112-116.

48. De Maeseneer M, Marcelis S, Jager T, Girard C, Gest T, Jamadar D. Spectrum of normal and pathologic findings in the region of the first extensor compartment of the wrist: sonographic findings and correlations with dissections. J Ultrasound Med 2009; 28:779-786.

49. Kamel M, Moghazy K, Eid H, Mansour R. Ultrasonographic diagnosis of de Quervain's tenosynovitis. Ann Rheum Dis 2002; 61:10341035.

50. Lee KH, Kang CN, Lee BG, Jung WS, Kim DY, Lee CH. Ultrasonographic evaluation of the first extensor compartment of the wrist in de Quervain's disease. J Orthop Sci 2014; 19:49-54.

51. Leversedge FJ, Cotterell IH, Nickel B, Crosmer M, Richard M, Angermeier E. Ultrasonography-guided de Quervain injection: accuracy and anatomic considerations in a cadaver model. J Am Acad Orthop Surg 2016; 24:399-404.

52. Orlandi D, Corazza A, Silvestri E, et al. Ultrasound-guided procedures around the wrist and hand: how to do. Eur J Radiol 2014; 83: 1231-1238.

53. Makkouk AH, Oetgen ME, Swigart CR, Dodds SD. Trigger finger: etiology, evaluation, and treatment. Curr Rev Musculoskelet Med 2008; 1:92-96.

54. Guerini H, Pessis E, Theumann N, et al. Sonographic appearance of trigger fingers. J Ultrasound Med 2008; 27:1407-1413.

55. Sato J, Ishii Y, Noguchi H, Takeda M. Sonographic appearance of the flexor tendon, volar plate, and Al pulley with respect to the severity of trigger finger. J Hand Surg Am 2012; 37:2012-2020.

56. Spirig A, Juon B, Banz Y, Rieben R, Vogelin E. Correlation between sonographic and in vivo measurement of Al pulleys in trigger fingers. Ultrasound Med Biol 2016; 42:1482-1490.

57. Grundberg $A B$, Reagan DS. Pathologic anatomy of the forearm: intersection syndrome. J Hand Surg Am 1985; 10:299-302.

58. Pantukosit S, Petchkrua W, Stiens SA. Intersection syndrome in Buriram Hospital: a 4-yr prospective study. Am J Phys Med Rehabil 2001; 80:656-661.

59. de Lima JE, Kim HJ, Albertotti F, Resnick D. Intersection syndrome: MR imaging with anatomic comparison of the distal forearm. Skeletal Radiol 2004; 33:627-631.

60. Parellada AJ, Gopez AG, Morrison WB, et al. Distal intersection tenosynovitis of the wrist: a lesser-known extensor tendinopathy with characteristic MR imaging features. Skeletal Radiol 2007; 36:203-208. 
61. Sato J, Ishii Y, Noguchi H. Clinical and ultrasound features in patients with intersection syndrome or de Quervain's disease. J Hand Surg Eur Vol 2016; 41:220-225.

62. Draghi F, Bortolotto C. Intersection syndrome: ultrasound imaging. Skeletal Radiol 2014; 43:283-287.

63. Montechiarello S, Miozzi F, D’Ambrosio I, Giovagnorio F. The intersection syndrome: ultrasound findings and their diagnostic value. J Ultrasound 2010; 13:70-73.

64. Christiaanse E, Jager T, Lenchik L, Buls N, Van Hedent E, De Maeseneer M. Thickness of extensor tendons at the proximal intersection: sonographic measurements in asymptomatic volunteers. J Ultrasound Med 2014; 33:2099-2103.

65. Budoff JE, Kraushaar BS, Ayala G. Flexor carpi ulnaris tendinopathy. J Hand Surg Am 2005; 30:125-129.

66. Kofman $\mathrm{KE}$, Schuurman $\mathrm{AH}, \mathrm{Mulder} \mathrm{MC}$, et al. The pisotriquetral joint: osteoarthritis and enthesopathy. J Hand Microsurg 2014; 6:18-25.

67. Wick MC, Weiss RJ, Arora R, et al. Enthesiopathy of the flexor carpi ulnaris at the pisiform: findings of high-frequency sonography. Eur $J$ Radiol 2011; 77:240-244.

68. Campbell D, Campbell R, O'Connor P, Hawkes R. Sports-related extensor carpi ulnaris pathology: a review of functional anatomy, sports injury and management. Br J Sports Med 2013; 47:1105-1111.

69. Sole JS, Wisniewski SJ, Newcomer KL, Maida E, Smith J. Sonographic evaluation of the extensor carpi ulnaris in asymptomatic tennis players. PM R 2015; 7:255-263.

70. Seki E, Ishikawa H, Murasawa A, et al. Dislocation of the extensor carpi ulnaris tendon in rheumatoid wrists using three-dimensional computed tomographic imaging. Clin Rheumatol 2013; 32:1627-1632.

71. Petchprapa CN, Meraj S, Jain N. ECU tendon "dislocation" in asymptomatic volunteers. Skeletal Radiol 2016; 45:805-812.

72. Iorio ML, Bayomy AF, Huang JI. Morphology of the extensor carpi ulnaris groove and tendon. J Hand Surg Am 2014; 39:2412-2416.

73. Allende C, Le Viet D. Extensor carpi ulnaris problems at the wrist: classification, surgical treatment and results. J Hand Surg Am 2005; 30:265-272.

74. Chang CY, Huang AJ, Bredella MA, Kattapuram SV, Torriani M. Association between distal ulnar morphology and extensor carpi ulnaris tendon pathology. Skeletal Radiol 2014; 43:793-800.

75. Inoue G, Tamura Y. Recurrent dislocation of the extensor carpi ulnaris tendon. BrJ Sports Med 1998; 32:172-174.

76. Lee KS, Ablove RH, Singh S, De Smet AA, Haaland B, Fine JP. Ultrasound imaging of normal displacement of the extensor carpi ulnaris tendon within the ulnar groove in 12 forearm-wrist positions. AJR Am J Roentgenol 2009; 193:651-655.

77. MacLennan AJ, Nemechek NM, Waitayawinyu T, Trumble TE. Diagnosis and anatomic reconstruction of extensor carpi ulnaris subluxation. J Hand Surg Am 2008; 33:59-64.

78. Pratt RK, Hoy GA, Bass Franzcr C. Extensor carpi ulnaris subluxation or dislocation? Ultrasound measurement of tendon excursion and normal values. Hand Surg 2004; 9:137-143.
79. El-Sheikh Y, Wong I, Farrokhyar F, Thoma A. Diagnosis of finger flexor pulley injury in rock climbers: a systematic review. Can J Plast Surg 2006; 14:227-231.

80. King EA, Lien JR. Flexor tendon pulley injuries in rock climbers. Hand Clin 2017; 33:141-148.

81. Klauser A, Frauscher F, Bodner G, et al. Finger pulley injuries in extreme rock climbers: depiction with dynamic US. Radiology 2002; 222:755-761.

82. Martinoli C, Bianchi S, Nebiolo M, Derchi LE, Garcia JF. Sonographic evaluation of digital annular pulley tears. Skeletal Radiol 2000; 29:387-391.

83. Schoffl I, Hugel A, Schoffl V, Rascher W, Jungert J. Diagnosis of complex pulley ruptures using ultrasound in cadaver models. Ultrasound Med Biol 2017; 43:662-669.

84. Teefey SA, Dahiya N, Middleton WD, Gelberman RH, Boyer MI. Ganglia of the hand and wrist: a sonographic analysis. AJR Am J Roentgenol 2008; 191:716-720.

85. Kichouh M, Vanhoenacker F, Jager T, et al. Functional anatomy of the dorsal hood or the hand: correlation of ultrasound and MR findings with cadaveric dissection. Eur Radiol 2009; 19:1849-1856.

86. Hame SL, Melone CP Jr. Boxer's knuckle: traumatic disruption of the extensor hood. Hand Clin 2000; 16:375-380, viii.

87. Hame SL, Melone CP Jr. Boxer's knuckle in the professional athlete. Am J Sports Med 2000; 28:879-882.

88. Kichouh $\mathrm{M}$, De Maeseneer $\mathrm{M}$, Jager $\mathrm{T}$, et al. Ultrasound findings in injuries of dorsal extensor hood: correlation with MR and follow-up findings. Eur J Radiol 201 1; 77:249-253.

89. Lopez-Ben R, Lee DH, Nicolodi DJ. Boxer knuckle (injury of the extensor hood with extensor tendon subluxation): diagnosis with dynamic US-report of three cases. Radiology 2003; 228: 642-646.

90. Taljanovic MS, Melville DM, Gimber LH, et al. High-resolution US of rheumatologic diseases. Radiographics 2015; 35:20262048.

91. Daenen B, Houben G, Bauduin E, Debry R, Magotteaux P. Sonography in wrist tendon pathology. J Clin Ultrasound 2004; 32:462-469.

92. Suresh E. Diagnosis of early rheumatoid arthritis: what the nonspecialist needs to know. J R Soc Med 2004; 97:421-424.

93. Orlandi D, Gitto S, Perugin Bernardi S, et al. Advanced power Doppler technique increases synovial vascularity detection in patients with rheumatoid arthritis. Ultrasound Med Biol 2017. doi: 10.1016/j.ultrasmedbio.2017.05.004.

94. Bortolotto C, Gregoli B, Coscia DR, Draghi F. Septic complications involving hand and wrist in patients with pre-existing rheumatoid arthritis: the role of magnetic resonance imaging and sonography. J Ultrasound 2012; 15:115-120.

95. Mandl P, Kurucz R, Niedermayer D, Balint PV, Smolen JS. Contributions of ultrasound beyond clinical data in assessing inflammatory disease activity in rheumatoid arthritis: current 
insights and future prospects. Rheumatology 2014; 53:21362142 .

96. Jacob D, Cohen M, Bianchi S. Ultrasound imaging of nontraumatic lesions of wrist and hand tendons. Eur Radiol 2007; 17: 2237-2247.

97. Bruyn GA, Hanova P, Iagnocco A, et al. Ultrasound definition of tendon damage in patients with rheumatoid arthritis: results of a OMERACT consensus-based ultrasound score focussing on the diagnostic reliability. Ann Rheum Dis 2014; 73:1929-1934.

98. Filippucci E, Gabba A, Di Geso L, Girolimetti R, Salaffi F, Grassi W. Hand tendon involvement in rheumatoid arthritis: an ultrasound study. Semin Arthritis Rheum 2012; 41:752-760.

99. Wang MY, Wang XB, Sun XH, Liu FL, Huang SC. Diagnostic value of high-frequency ultrasound and magnetic resonance imaging in early rheumatoid arthritis. Exp Ther Med 2016; 12:3035-3040.

100. Carotti M, Salaffi F, Morbiducci J, et al. Colour Doppler ultrasonography evaluation of vascularization in the wrist and finger joints in rheumatoid arthritis patients and healthy subjects. Eur J Radiol 2012; 81:1834-1838.

101. Navalho M, Resende C, Rodrigues AM, et al. Bilateral evaluation of the hand and wrist in untreated early inflammatory arthritis: a comparative study of ultrasonography and magnetic resonance imaging. J Rheumatol 2013; 40:1282-1292.

102. Bakewell CJ, Olivieri I, Aydin SZ, et al. Ultrasound and magnetic resonance imaging in the evaluation of psoriatic dactylitis: status and perspectives. J Rheumatol 2013; 40:1951-1957.
103. Brockbank JE, Stein M, Schentag CT, Gladman DD. Dactylitis in psoriatic arthritis: a marker for disease severity? Ann Rheum Dis 2005; 64:188-190.

104. Milosavljevic J, Lindqvist U, Elvin A. Ultrasound and power Doppler evaluation of the hand and wrist in patients with psoriatic arthritis. Acta Radiol 2005; 46:374-385.

105. Coates LC, Hodgson R, Conaghan PG, Freeston JE. MRI and ultrasonography for diagnosis and monitoring of psoriatic arthritis. Best Pract Res Clin Rheumatol 2012; 26:805-822.

106. De Filippis LG, Caliri A, Lo Gullo R, et al. Ultrasonography in the early diagnosis of psoriasis-associated enthesopathy. Int $\mathrm{J}$ Tissue React $2005 ; 27: 159-162$.

107. Spadaro A, Lubrano E. Psoriatic arthritis: imaging techniques. Reumatismo 2012; 64:99-106.

108. Cohen M. US imaging in operated tendons. J Ultrasound 2012; 15 : $69-75$.

109. Gitto S, Draghi AG, Bortolotto C, Draghi F. Sonography of the Achilles tendon after complete rupture repair: what the radiologist should know. J Ultrasound Med 2016; 35:25292536.

110. Guillin R, Bianchi S. Sonographic assessment of orthopedic hardware impingement on soft tissues of the limbs.J Ultrasound 2012; 15:50-55.

111. Carbo S, Roson N, Vizcaya S, Escribano F, Zarcero M, Medrano S. Can ultrasound help to define orthopedic surgical complications? Curr Prob Diagn Radiol 2006; 35:75-89. 